\title{
A Pharmacological Chaperone Molecule Induces Cancer Cell Death by Restoring Tertiary DNA Structures in Mutant hTERT Promoters
}

Hyun-Jin Kang, ${ }^{1}$ Yunxi Cui, ${ }^{2}$ Holly Yin, ${ }^{3}$ Amy Scheid, ${ }^{4}$ William P. D. Hendricks, ${ }^{3}$ Jessica Schmidt,${ }^{5}$ Aleksandar Sekulic, ${ }^{5}$ Deming Kong, ${ }^{6}$ Jeffrey M. Trent, ${ }^{3}$ Vijay Gokhale, ${ }^{7}$ Hanbin Mao, ${ }^{2}$ Laurence H.

$$
\text { Hurley*1,7,8 }
$$

${ }^{1}$ University of Arizona, College of Pharmacy, 1703 East Mabel Street, Tucson, Arizona 85721

${ }^{2}$ Department of Chemistry and Biochemistry and School of Biomedical Sciences, Kent State University, Kent, Ohio, 44242 USA

${ }^{3}$ Translational Genomics Research Institute, 445 North Fifth Street, Phoenix, Arizona 85004 USA

${ }^{4}$ University of Arizona, College of Science, 1040 East Fourth Street, Tucson, Arizona 85721 USA

${ }^{5}$ Mayo Clinic, Department of Dermatology, 13400 East Shea Boulevard, Scottsdale, Arizona 85259 USA ${ }^{6}$ State Key Laboratory of Medicinal Chemical Biology, College of Chemistry, Nankai University, Tianjin 300071, People's Republic of China

${ }^{7}$ BIO5 Institute, 1657 East Helen Street, Tucson, Arizona 85721 USA

${ }^{8}$ Arizona Cancer Center, 1515 North Campbell Avenue, Tucson, Arizona 85724 USA

*Corresponding Author: Laurence Hurley

Email: hurley@pharmacy.arizona.edu

Tel: 520-626-5622 


\begin{abstract}
Activation of human telomerase reverse transcriptase (hTERT) is necessary for limitless replication in tumorigenesis. Whereas hTERT is transcriptionally silenced in normal cells, most tumor cells reactivate hTERT expression by alleviating transcriptional repression through diverse genetic and epigenetic mechanisms. Transcription-activating hTERT promoter mutations have been found to occur at high frequencies in multiple cancer types. These mutations have been shown to form new transcription factor binding sites that drive hTERT expression, but this model cannot fully account for differences in wildtype (WT) and mutant promoter activation and has not yet enabled a selective therapeutic strategy. Here we demonstrate a novel mechanism by which promoter mutations activate hTERT transcription, which also sheds light on a unique therapeutic opportunity. Promoter mutations occur in a core promoter region that forms tertiary structures consisting of a pair of G-quadruplexes involved in transcriptional silencing. We show that promoter mutations exert a detrimental effect on the folding of one of these Gquadruplexes, resulting in a nonfunctional silencer element that alleviates transcriptional repression. We have also identified a small drug-like pharmacological chaperone (pharmacoperone) molecule, GTC365, that acts at an early step in the G-quadruplex folding pathway to redirect mutant promoter G-quadruplex misfolding, partially reinstate the correct folding pathway, and reduce hTERT activity through transcriptional repression. This transcription-mediated repression effects cancer cell death through multiple routes including both induction of apoptosis through inhibition of hTERT's role in regulating apoptosis-related proteins and inducing senescence by decreasing telomerase activity and telomere length. We demonstrate the selective therapeutic potential of this strategy in melanoma cells that overexpress hTERT.
\end{abstract}




\section{INTRODUCTION}

Activation of telomerase is a hallmark of cancer $^{1}$ in the early stages of tumorigenesis and is associated with telomere elongation, genetic instability, and subsequent immortalization of cells. Several therapeutic strategies for overcoming activated telomerase have been explored, ${ }^{2}$ including targeting the telomerase holoenzyme or the human telomerase reverse transcriptase (hTERT) subunit, targeting telomeric Gquadruplexes, inhibiting telomerase RNA, and using immune therapy directed at hTERT as a tumor antigen. Imetelstat, an antisense 13-mer oligonucleotide targeted to hTERT, has shown preclinical promise with anticancer activity in breast, brain, pancreas, and liver cancer models. ${ }^{3-8}$ However, clinical trials in breast, lung, and pediatric brain cancer were halted due to hematopoietic toxicity that may have resulted from nonselective hTERT inhibition in stem cells. ${ }^{9-11}$ Trials are now ongoing in myeloproliferative disease with promising results in myelofibrosis and essential thrombocythemia. ${ }^{12,13}$

hTERT is the catalytic subunit of the telomerase holoenzyme. In addition, hTERT has various telomere-independent functions, including enhancement of cellular proliferation, initiation of the DNA damage response through changes in chromatin structure, ${ }^{14}$ and inhibition of apoptosis by upregulation of BCL2 expression. ${ }^{15}$ These functions are independent of each other. ${ }^{16}$ Expression of hTERT is usually inactivated in normal cells, although some cells with high rates of self-renewal, such as stem cells and cells in the intestine and ovary, depend on hTERT to maintain telomere length. ${ }^{17-19}$ Overexpression of hTERT for cell immortalization or telomerase activation occurs in several ways, including increased gene copy number ${ }^{20,21}$ and transcriptional modulation..$^{22,23}$ At the transcriptional level, the hTERT promoter does not have TATA or CAAT boxes ${ }^{24}$ but does have several transcription factor binding sites within 1 $\mathrm{Kb}$ of the transcription start site and is controlled by epigenetic changes, such as chromatin remodeling or methylation of the $\mathrm{CpG}$ islands in the promoter region. ${ }^{25,26}$ With this transcription machinery, $0.004 \mathrm{RNA}$ molecules per cell in telomerase-negative normal cells are elevated to $>0.2$ per cell in telomerase-positive tumor cells and may range as high as hundreds of copies per cell, ${ }^{22,27,28}$ showing a strong correlation between telomerase activity and hTERT transcription level. Although hTERT is overexpressed at various 
levels in more than $90 \%$ of cancers, it is the rate-limiting component of the telomerase holoenzyme and expression of only small amounts of hTERT that appear to be necessary for cellular immortalization. ${ }^{18,29,30}$ Therefore, therapeutic hTERT inhibition may entail unique stoichiometric requirements.

The essential region for activation of hTERT transcription is the core promoter region, from the transcription start site to -181 base pairs upstream (Figure 1A). This region includes the E-box for MYC, CCGCCC/GGCGGG repeats for Sp1, and other elements for transcription activation. ${ }^{24}$ An additional upstream region likely contains transcription-repressing elements, because the longer promoter region shows decreased promoter activity. ${ }^{31}$ This core promoter region becomes nuclease sensitive during cell proliferation. ${ }^{32}$ Because the hTERT core promoter is selectively activated in cancer cells, it is targeted for gene therapy by utilizing the promoter for expression of cytotoxic tumor-suppressing proteins. $^{33}$

G-quadruplexes are commonly found in promoter elements of many genes and are known to function as silencer elements. ${ }^{34}$ For example, in the MYC promoter nucleolin binds to this structure to repress transcription, ${ }^{35}$ and we and the group at NCI have also identified small molecules that directly target the MYC promoter G-quadruplex to repress gene transcription using an exon-specific assay. ${ }^{36,37} \mathrm{~A}$ comprehensive review on drug targeting of G-quadruplexes has recently appeared. ${ }^{38}$

In the case of BCL2 we have also shown that the i-motif found on the C-rich strand functions as the transcriptional activator by binding to hnRNP LL. ${ }^{39,40}$ For the hTERT promoter we have previously shown, by various biochemical and biophysical experiments, that the silencer element consists of an unusually complex structure that forms end-to-end stacked G-quadruplex structures from 12 G-tracts (Figure 1B). ${ }^{41}$ One of these structures, formed by G-tracts 5-12, has a unique 3:26:1 loop configuration (Figure 1C). Furthermore the 26-base internal loop is a hairpin structure that is responsible for the unique cooperative folding of this G-quadruplex, a process more commonly associated with pre-mRNA. This structure is important in the formation of the correctly folded structure and transcription silencing (Figure 1D). ${ }^{42}$ An alternative structure that lacks this hairpin loop has been proposed. ${ }^{43}$ Significantly, the mouse TERT lacks these 12 G-tracts and has a 16-fold higher transcription activation level. ${ }^{44}$ 

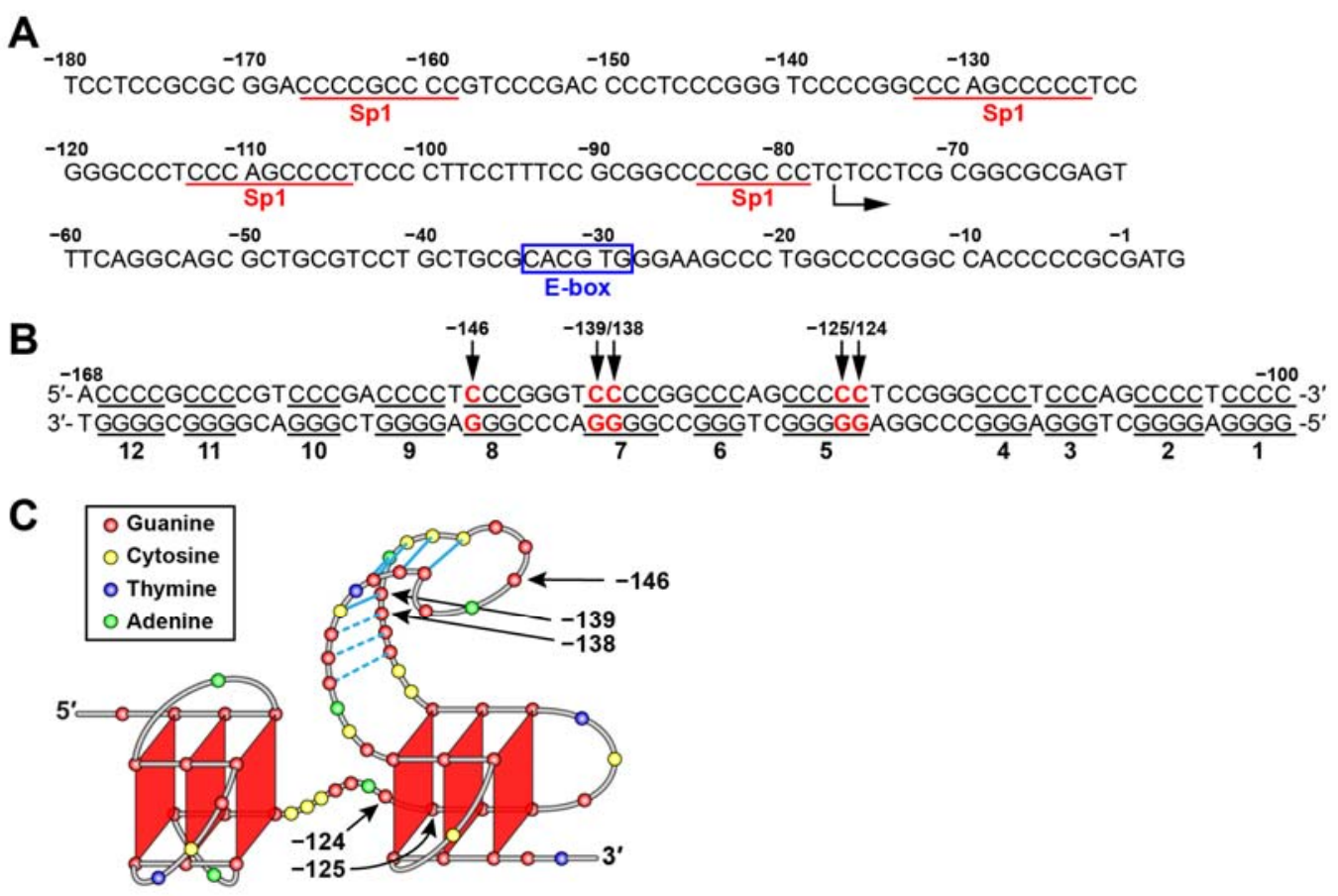
G-tracts 1-4
$(1: 3: 1)$
G-tracts 5-12
(3:26:1)

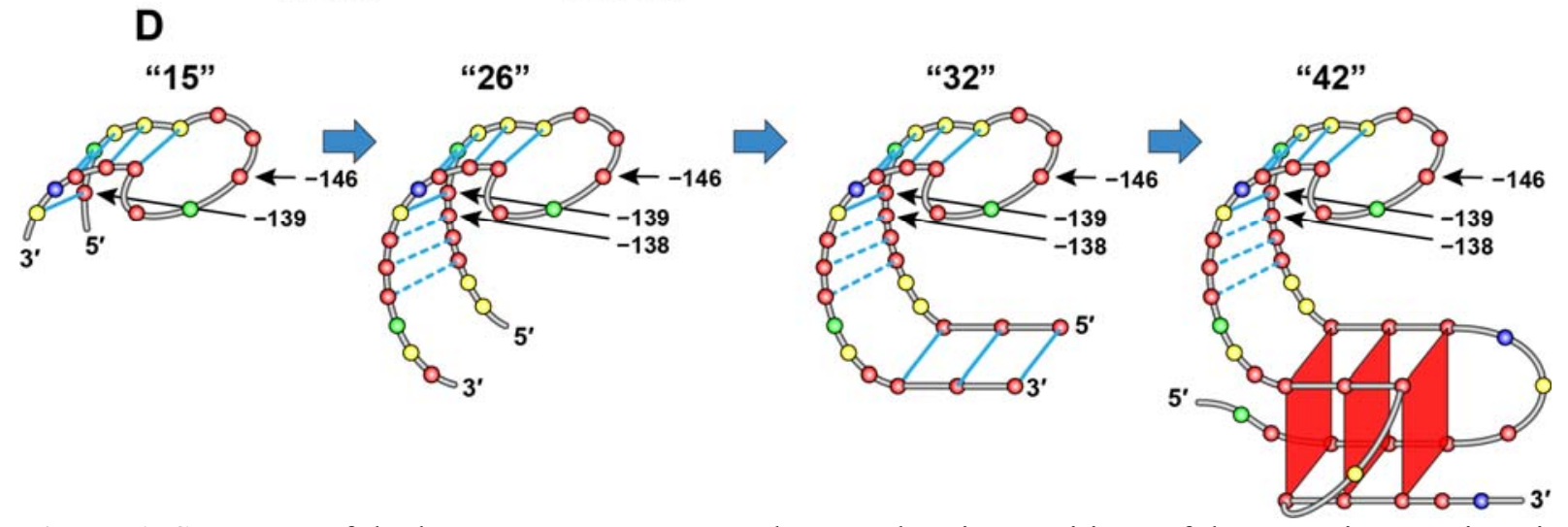

Figure 1. Sequence of the hTERT core promoter element showing positions of the somatic mutations in the duplex and G-quadruplexes and the cooperative folding process. (A) Sequence of the core promoter element of the hTERT promoter. (B) Twelve G/C tracts in the hTERT core promoter region showing in red the positions of the somatic mutations located $-124,-124 / 125,-138 / 139$, and -146 from the ATG start site. The two G-quadruplex-forming sequences are located between positions -168 and -100 . (C) DMS-predicted folding patterns of the 1-4 and 5-12 G-quadruplexes showing the positions of the somatic mutations. Somatic mutations (C/G to T/A) located at -124 and $-124 / 125$ (G-tract 5), $-138 / 139$ (G-tract 7), and -146 (G-tract 8) are positioned adjacent to and in the $3^{\prime}$ tetrad, the stem of the hairpin loop, and the central loop of the hairpin respectively of the 5-12 G-quadruplex. (D) Schematic of folding transitions for 5-12 G-quadruplex hTERT fragment in the core promoter element. Arrows indicate the positions of the mutations in this fragment. 
Several groups have recently demonstrated that diverse tumor types including melanoma, glioblastoma, bladder cancer, and hepatocellular carcinoma have mutually exclusive somatic mutations within the hTERT promoter region at positions $-124,-124 / 125,-138 / 139$, and $-146 .{ }^{45-50}$ More than 50 tumor types have now been shown to bear these hotspot mutations, and they often occur as an early driving step in tumorigenesis. ${ }^{51}$ hTERT promoter mutations may additionally bear value as prognostic and diagnostic biomarkers insofar as they have been shown to be associated with decreased overall survival and aggressive histotypes in many cancers. ${ }^{51}$

Through a G-to-A mutation (G/A) in the antisense strand, hTERT promoter mutations are proposed to generate an ETS/TCF element (CCGGAA) that would increase binding of the ETS transcription factor for activation of hTERT transcription. ${ }^{45,46}$ In addition, it has recently been suggested that the mutations found in glioblastoma multiforme could lead to recruitment of multimeric GA-binding protein (GABP) transcription factors to activate hTERT. ${ }^{52}$ However, these models cannot fully account for promoterdriven hTERT transcriptional modulation in part because genetic background may play a role in enabling aberrant transcription factor binding. For example, both BRAF and EGFR mutations frequently co-occur with hTERT promoter mutations in melanoma and glioblastoma and may be necessary for GABPmediated activation prior to its interaction with the mutant hTERT promoter. ${ }^{45,47,53}$ While both types of allelic changes could contribute to the activation of hTERT, we provide evidence here that a third mechanism, independent of genomic background, involves inactivation of the silencer element and is also an important contributor to the activation of hTERT. Critically, this finding also provides a direct opportunity to reverse the effects of these somatic mutations. ${ }^{52}$ Significantly, these mutations are also localized in the 5-12 G-quadruplex with the 3:26:1 loop configuration.

We have previously demonstrated that mutations in the hairpin loop result in changes in both the stability and the folding pattern of the G-quadruplex, based on DMS footprinting, which identifies those guanines involved in the formation of the tetrads that are the building blocks for the G-quadruplexes. ${ }^{41}$ Furthermore, single-molecule laser tweezers experiments showed that the initial folding of the hairpin plays a pivotal role in forming the fully folded species, since mutation resulted in only $4 \%$ of the fully 
folded form. ${ }^{42}$ We therefore set out to characterize the effect of hTERT promoter mutations on secondary DNA structures in the hTERT promoter and to determine whether the unique properties of these structures could be manipulated with small molecules as a therapeutic strategy for transcriptional silencing-mediated hTERT inhibition.

\section{METHODS}

Circular dichroism. Oligomers of WT, G124A, G124/125A, G138/139A, and G146A were synthesized and HPSF-purified by MGW Operon, Inc. (Table S3). For CD analysis, oligomers ( $5 \mu \mathrm{M})$ in a buffer containing $10 \mathrm{mM}$ Tris- $\mathrm{HCl}(\mathrm{pH} 7.5)$ and $140 \mathrm{mM} \mathrm{KCl}$ were annealed by heating for $5 \mathrm{~min}$ at $95{ }^{\circ} \mathrm{C}$ and subsequent slow cooling to room temperature. For the $\mathrm{CD}$ analysis of the complex of oligomers and compounds, oligomers $(5 \mu \mathrm{M})$ in a buffer containing $10 \mathrm{mM}$ Tris- $\mathrm{HCl}(\mathrm{pH} 7.5)$ and $5 \mathrm{mM} \mathrm{KCl}$ for GTC365 or $1 \mathrm{mM} \mathrm{KCl}$ for BRACO-19 were annealed. Oligomers and GTC365 or BRACO-19 were incubated overnight at room temperature. For the full-length C-rich strand, the oligomer in a buffer of 10 $\mathrm{mM}$ Na cacodylate ( $\mathrm{pH}$ 6.6) was annealed and then incubated with GTC365 overnight. CD analysis was conducted on a Jasco 810 spectropolarimeter (Jasco, Easton, MD) using a quartz cell with $1 \mathrm{~mm}$ of path length, $1 \mathrm{~nm}$ of band width, and $1 \mathrm{~s}$ of response time for spectra at $20^{\circ} \mathrm{C}$. Melting curves for the determination of $T_{\mathrm{m}}$ were obtained by recording ellipticity at $262 \mathrm{~nm}$ with increasing temperatures from $25^{\circ} \mathrm{C}$ to $95^{\circ} \mathrm{C}$ at a rate of $1.6{ }^{\circ} \mathrm{C} / \mathrm{min} . T_{\mathrm{m}}$ of the C-rich strand with GTC365 was obtained from the CD signal at $286 \mathrm{~nm}$ within $10-60{ }^{\circ} \mathrm{C}$.

For the kinetics analysis using the temperature-jump method, the oligo in a buffer containing $10 \mathrm{mM}$ Tris- $\mathrm{HCl}(\mathrm{pH} 7.5)$ was heated for $1 \mathrm{~min}$ at $95^{\circ} \mathrm{C}$ and then a mixture of $\mathrm{KCl}$ and compound was added and incubated for $1 \mathrm{~min}$. Meanwhile, the $\mathrm{CD}$ cuvette was also heated at $95^{\circ} \mathrm{C}$. As soon as the sample in the $\mathrm{CD}$ cuvette at the high temperature was placed in the CD chamber, a time-dependent $\mathrm{CD}$ signal at $262 \mathrm{~nm}$ was recorded immediately. The initial folding rate was determined by one-phase association curve fitting (equation 1) of kinetics curve using GraphPad Prism 5: 


$$
\mathrm{Y}=\mathrm{Y} 0+(\mathrm{Plateau}-\mathrm{Y} 0) *\left(1-e^{-k x}\right)
$$

where $\mathrm{Y}$ is the $\mathrm{CD}$ signal at any time point $x, \mathrm{Y} 0$ is the $\mathrm{Y}$ value when time $(x)$ is zero, Plateau is the $\mathrm{Y}$ value at infinite time, and $k$ is the rate constant.

Single-molecule laser tweezers experiments. Preparation of the DNA constructs. The DNA constructs that contain the wild-type (WT) or mutant single-stranded hTERT 5-12 fragments were prepared by sandwiching the target sequence (WT: 5'-

GGGGGCTGGGCCGGGGACCCGGGAGGGGTCGGGACGGGGCGGGGC and 5'GCCCCGCCCCGTCCCGACCCCTCCCGGGTCCCCGGCCCAGCCCCC; G124/125A mutant: 5'AAGGGCTGGGCCGGGGACCCGGGAGGGGTCGGGACGGGGCGGGGC and 5'GCCCCGCCCCGTCCCGACCCCTCCCGGGTCCCCGGCCCAGCCCㄸT; G138/139A mutant: GGGGGCTGGGCCGGAAACCCGGGAGGGGTCGGGACGGGGCGGGGC and 5'GCCCCGCCCCGTCCCGACCCCTCCCGGGTTTCCGGCCCAGCCCCC; mutated bases are underlined) between two double-stranded DNA handles, according to published procedures ${ }^{54}$ Five deoxythymidines were added at both ends of the hTERT 5-12 fragment to reduce the interference from the double-stranded DNA handles on the target sequence. Briefly, the 2690-base-pair double-stranded DNA handle was prepared through restriction enzyme digestion of the pEGFP vector (Clontech, Mountain View, CA). In the first step, the vector was digested by SacI and EagI restriction enzymes, followed by purification with agarose gel. The EagI end of the DNA fragment was labeled with digoxigenin using terminal deoxynucleotidyl transferase. The other double-stranded DNA handle (2028 base pairs) was prepared by PCR using the PBR322 plasmid template and a biotinylated primer. The PCR product was subsequently digested with $\mathrm{XbaI}$ restriction enzyme. The middle section that contains the target hTERT 5-12 fragment was hybridized from three single-stranded DNA targets: 5'-CTA GAC GGT GTG AAATAC CGC ACA GAT GCGTTT TTA AGG GCT GGG CCG GGG ACC CGG GAG GGG TCG GGA CGG GGC GGG GTT TTT GCC AGC AAG ACGTAG CCC AGC GCGTC-3', 5'-CGC ATC 
TGT GCG GTA TTT CAC ACC GT-3', and 5'-GGC CGA CGC GCT GGG CTA CGT CTT GCT GGC-

3'. Finally, ligation between the two long double-stranded DNA handles and this double-stranded

DNA/single-stranded DNA middle section was achieved using T4 DNA ligase.

To perform the mechanical unfolding experiments, $1 \mu \mathrm{L}$ of the $2.10 \mu \mathrm{M}$ polystyrene beads $(0.5 \%$ $\mathrm{w} / \mathrm{v})$ coated with digoxigenin antibody was incubated with $0.1 \mathrm{ng}\left(3.5 \times 10^{-17} \mathrm{~mol}\right)$ of the DNA prepared above in $5 \mu \mathrm{L}$ of specific buffers (10 mM Tris buffer at pH 7.4 or $50 \mathrm{mM}$ MES buffer at $\mathrm{pH}$ 5.5) supplemented with $100 \mathrm{mM} \mathrm{KCl}$ or $\mathrm{LiCl}$. After 30 min of incubation, the DNA construct was immobilized on the surface of the beads through affinity interactions. The incubation mixture was diluted to $800 \mu \mathrm{L}$ with the same buffer for injection into a microfluidic chamber. The DNA construct linked to the $2.10 \mu \mathrm{M}$ beads was subsequently tethered to the $1.87 \mu \mathrm{M}$ polystyrene beads coated by streptavidin through the biotin-labeled DNA construct.

The double-stranded hTERT construct was prepared through a similar strategy. During preparation, two complementary single-stranded DNA oligomers with respective G-rich and C-rich hTERT sequences were annealed to form a double-stranded fragment, which was then ligated with the two double-stranded DNA handles to produce the final target sequence.

Single-molecule force-ramp assay. The laser-tweezers instrument has been described previously. ${ }^{55}$ Briefly, a home-build dual-trap laser (1064 nm, 4 W, CW mode, BL-106C, Spectra-Physics) was used as the trapping laser. P- and S-polarized laser light from the same laser source constituted two traps. ${ }^{55}$ The mobile laser trap controlled by a motorized mirror grabbed the $2.10 \mu \mathrm{M}$ bead ligated with target DNA and the other trap grabbed the $1.87 \mu \mathrm{M}$ bead. While moving the mobile laser trap, the two beads got close, and a DNA tether can form between them. After this, the two beads we moved apart to increase the tension on the DNA tether with a loading rate of $5.5 \mathrm{pN} / \mathrm{s}$, and the force-extension $(F-X)$ curves were recorded using the LabVIEW program (National Instruments Corp., Austin, TX).

The $F$ - $X$ curves were filtered by Savitzky-Golay function with a $10 \mathrm{~ms}$ time constant in the MATLAB program (The Math Works, Natick, MA). The change in extension $(\Delta x)$ at a given force was 
obtained from the subtraction between the stretching and relaxing curves at that force. The change-incontour length $(\Delta \mathrm{L})$ was calculated based on the $\Delta \mathrm{x}$ through the worm-like chain model (equation 2$)^{56}$ :

$$
\frac{\Delta \mathrm{x}}{\Delta \mathrm{L}}=1-\frac{1}{2} \sqrt{\frac{\mathrm{k}_{\mathrm{B}} \mathrm{T}}{\mathrm{FP}}}+\frac{\mathrm{F}}{\mathrm{S}}
$$

where $\mathrm{k}_{\mathrm{B}}$ is the Boltzmann constant, $\mathrm{T}$ is temperature, $\mathrm{P}$ is persistence length $(50.8 \mathrm{~nm})$, and $\mathrm{S}$ is the stretching modulus (1243 pN) for double-stranded DNA handles. ${ }^{57}$

The PodNano analysis was performed according to the literature. ${ }^{58}$ Briefly, we expanded each $\Delta \mathrm{L}$ with a Gaussian kernel whose width was determined by the average standard error measured before and after each unfolding transition. Resampling was repeated 5000 times to identify the most likely $\Delta \mathrm{L}$ populations in each of the resampling. These $\Delta \mathrm{L}$ populations were then presented in histograms (shown in Figures 2C, 3E, and 5D).

After calculating $\Delta \mathrm{L}$ of the structure, we can estimate the number of nucleotides (nt) contained in a particular length based on the $\Delta \mathrm{L}$ (equation 3$)^{59}$ :

$$
\mathrm{n}=\frac{\Delta \mathrm{L}+x}{L_{\mathrm{nt}}}
$$

where $x$ is the end-to-end distance for G-quadruplex or i-motif structures $(0.5-1.5 \mathrm{~nm})^{54}$ and $L_{\mathrm{nt}}$ is the contour length per nucleotide. $L_{\mathrm{nt}}$ is located in the range of $0.40-0.45 \mathrm{~nm} / \mathrm{nt}$ for single-stranded DNA and $0.30-0.35 \mathrm{~nm} / \mathrm{bp}$ for double-strand DNA. ${ }^{60}$

Using these single-molecule approaches, we then investigated the interactions of the 5-12 hTERT fragments with $2 \mu \mathrm{M}$ GTC365 and BRACO-19 in $10 \mathrm{mM}$ Tris buffer supplemented with $100 \mathrm{mM} \mathrm{KCl}$ at $\mathrm{pH}$ 7.4. The typical curves obtained from the single molecule assay are shown in Figure S1. 
DMS footprinting. FAM-labeled oligomers (WT, G124A, G124/125A, G138/139A, and G146A) were purchased from MGW Operon Inc. and PAGE purified (Table S3). These oligomers (25 nM) were dissolved in a buffer $(10 \mathrm{mM}$ Tris-HCl, $\mathrm{pH} 8.1$, and $140 \mathrm{mM} \mathrm{KCl})$ and annealed by heating for $5 \mathrm{~min}$ at $95^{\circ} \mathrm{C}$ and subsequent slow cooling to room temperature. For the footprinting with GTC 365 , the methods were modified from the literature. ${ }^{61}$ A FAM-labeled oligomer of WT in a buffer containing $50 \mathrm{mM} \mathrm{Na}$ cacodylate (pH 7.6) and $5 \mathrm{mM} \mathrm{KCl}$ was annealed. GTC365 in 20\% DMSO was added to oligomers to produce 1,2 , and 4 equiv. and then incubated at $37^{\circ} \mathrm{C}$ for $1 \mathrm{~h}$. For the DMS reaction, oligomers were incubated with $2 \mu \mathrm{g}$ of salmon sperm DNA (Sigma, D1626) and 5\% DMS in 50\% ethanol for 8 min. The reaction was stopped by $\beta$-mercaptoethanol and then subjected to ethanol precipitation and cleavage by $10 \%$ piperidine with incubation at $93{ }^{\circ} \mathrm{C}$ for $15 \mathrm{~min}$. Cleaved product was washed twice by water and then separated by $15 \%$ denaturing PAGE with $7 \mathrm{M}$ urea. Fluorescence of separated cleavage product was detected by Bio-Rad PharosFX ${ }^{\mathrm{TM}}$ Plus, and the band densitogram was obtained by ImageJ.

FRET assay for compound screening and determination of $\mathbf{K}_{\mathbf{d}}$ value. FRET probes of WT, G124/125A, and G146A of the 5-12 G-quadruplex were synthesized and labeled with FAM (Ex. 490 nm/Em. $520 \mathrm{~nm}$ ) and TAMRA (Ex. $560 \mathrm{~nm} / \mathrm{Em} .580 \mathrm{~nm}$ ) at each end by MGW Operon Inc. (Table S3). The WT probe $(50 \mathrm{nM})$ was annealed in a buffer containing $10 \mathrm{mM}$ Tris- $\mathrm{HCl}(\mathrm{pH} 7.5)$ and $5 \mathrm{mM} \mathrm{KCl}$ by heating at $95^{\circ} \mathrm{C}$ for $5 \mathrm{~min}$ and slowly cooling to room temperature. Compounds $(50 \mu \mathrm{M})$ and probe were incubated for $1 \mathrm{~h}$ at room temperature. The same volume of DMSO served as a control. For $\mathrm{K}_{\mathrm{d}}$ value determination, the WT, G124/125A, and G146A probes were annealed by heating for $5 \mathrm{~min}$ at $95^{\circ} \mathrm{C}$ and subsequent slow cooling to room temperature, and then several concentrations of compound were treated for $1 \mathrm{~h}$ at room temperature. Dose-dependent fluorescence intensity at $520 \mathrm{~nm}$ was measured by a microplate reader (BioTek Synergy HT). The data were corrected with the blank signal of buffer and compound. The relative fluorescence intensity compared to DMSO was used for binding curve fitting to determine $\mathrm{K}_{\mathrm{d}}$ value using GraphPad Prism software. 
Cell cultures. UACC-383 (G138/139A), UACC-903 (G124A), and additional UACC cell lines described in Table S2. Cells were cultured in media of RPMI-1640 with 10\% FBS and 1\% penicillin/streptomycin. For melanoma cells UACC-2512 (WT), UACC-3090 (G124A), UACC-2528 (G124/125A), and UACC1729 (G146), 20\% FBS was included in the RPMI media instead of 10\% FBS. NHM-002 cells were cultured in Medium 254 with the addition of Human Melanocyte Growth Supplement. Cells were incubated at $37^{\circ} \mathrm{C}$ with $5 \% \mathrm{CO}_{2}$.

Sequencing analysis. Sequencing analysis was performed as previously reported using capillary Sanger sequencing. Sequencing primers for each gene are as previously reported: BRAF, ${ }^{62} \mathrm{NRAS},{ }^{62} \mathrm{KRAS},{ }^{63}$ CDKN2A, ${ }^{64} \mathrm{TP} 53,{ }^{65}$ and the TERT promoter. ${ }^{45}$

qPCR. MCF7 and melanoma cells were treated with GTC365 and BRACO-19 for $72 \mathrm{~h}$. Total RNA was extracted using an RNeasy mini-prep kit (Qiagen) and quantitated by measuring absorbance at $260 \mathrm{~nm}$. cDNA was synthesized using a Takara PrimeScript ${ }^{\mathrm{TM}}$ RT Reagent Kit with gDNA eraser and then used as a template for qPCR. The qPCR was performed using Kapa Probe Fast qPCR Master Mix with ABI TaqMan ${ }^{\circledR}$ probes of hTERT (Hs00972656_m1), BCL2 (HS00608023_m1, FAM-labeled), MYC (Hs00153408_m1) or BAX (Hs01016552-g1), and GAPDH (Hs02758991_g1, VIC-labeled). The Ct values were measured by running Rotor-Gene Q, and the relative quantity of hTERT, BCL2, and MYC mRNA was obtained compared to GAPDH as an internal control.

Luciferase assay. From gDNA extracted from HeLa cells, the hTERT core promoter region, including $-350 \mathrm{bp}$ to +12 from the transcription start site, was amplified using a pair of primers, including KpnI and NheI restriction sites. This method was used for cloning of the pGL3 construct with the WT hTERT core promoter sequence. Mutant constructs were generated by PCR-based site-directed mutagenesis. For the Ebox mutant, the WT CACGTG was replaced by TTTGTG to interrupt the E-box. The sequence of each construct was confirmed by sequencing analysis. MCF7 cells in a 24-well plate were transfected with 200 
ng of pGL3 construct and 5 ng of pRL-TK for normalization of activity of firefly luciferase expressed from the pGL3 construct. by FuGENE® HD Transfection Reagent and then incubated for 6 h. Media were replaced by fresh ones and the cells were treated with GTC365 or BRACO-19. The same volume of DMSO served as a control. After $24 \mathrm{~h}$ of incubation, cells were lysed by passive lysis buffer (Promega) and subjected to dual-luciferase assay (Promega) using an FB12 luminometer. The ratio of firefly to renilla luciferase activity was normalized to the DMSO to obtain the relative luciferase activity.

Establishment of stable cell lines overexpressing hTERT. The pCDNA-3XHA-hTERT plasmid containing hTERT driven by the CMV promoter was obtained from Addgene (ID:51637) deposited by Dr. Steven Artandi. ${ }^{66}$ MCF7 cells in a 24-well plate were transfected with this plasmid (250 ng) using FuGENE® HD Transfection Reagent for 24 h. Cells were treated with several concentrations of G418 $(0.1-1 \mathrm{mg} / \mathrm{mL})$ and an antibiotic for colony selection for four weeks, and then one colony was selected for further culture. The expression of ectopic hTERT with HA-tag was confirmed by immunoblot analysis using antibody against HA-tag (Santa Cruz, sc-805, 1:250 in TBS-T buffer with 5\% BSA) as described just below (Immunoblot analysis) and qPCR as described above.

Immunoblot analysis. GTC365- or DMSO-treated MCF7 cells were lysed by RIPA buffer, and the supernatant of lysate was obtained by centrifugation at $14000 \mathrm{rpm}$ for $15 \mathrm{~min}$. The concentration of the whole cellular protein was determined by Bradford assay. The same amount of proteins (120 $\mu \mathrm{g}$ for hTERT and $50 \mu \mathrm{g}$ for PARP) was separated on $8 \%$ SDS-PAGE and transferred to PVDF membrane in 20\% MeOH/1X Tris-glycine. The membrane was incubated in a blocking buffer containing 5\% BSA/5\% non-fat milk with TBS-T $(0.1 \%$ Tween 20$)$ for $90 \mathrm{~min}$ at room temperature prior to overnight incubation with hTERT antibody (1:200, Santa Cruz \#H231, pAb) and PARP antibody (1:1000, Cell Signaling \#9542) in 5\% BSA/TBS-T buffer at $4{ }^{\circ} \mathrm{C}$. This membrane was incubated with $\beta$-actin antibody against mouse (Cell Signaling \#3700, mAb, 1:2,000) for $2 \mathrm{~h}$ at room temperature. The membrane was incubated with secondary antibody, goat anti-rabbit IgG $(\mathrm{H}+\mathrm{L})$ DyLight ${ }^{\circledR} 800(1: 7,500)$, and goat anti-mouse $\operatorname{IgG}$ 
$(\mathrm{H}+\mathrm{L})$ DyLight ${ }^{\circledR} 680(1: 7,500)$, depending on the source of antibodies, in 5\% non-fat milk/TBS-T for 90 min at room temperature. LI-COR was used to detect the immunocomplex band.

TRAP assay. Compound-treated MCF7 cells were washed with cold D-PBS twice and then collected using a cell scraper. Cell pellet was resuspended in a lysis buffer including $10 \mathrm{mM}$ Tris-HCl (pH7.5), 1 $\mathrm{mM} \mathrm{MgCl} 2,1 \mathrm{mM}$ EGTA, $0.5 \%$ CHAPS, $10 \%$ Glycerol, $5 \mathrm{mM} \beta$-mercaptoethanol, $1 \mathrm{X}$ protease inhibitor cocktail (Sigma P8340), and 0.2 U/ $\mu \mathrm{L}$ of RiboLock RNase Inhibitor (Thermo Fisher) and kept on ice for $30 \mathrm{~min}$. Supernatant was obtained by centrifugation at $14,000 \mathrm{rpm}$ for $20 \mathrm{~min}$, and the concentration of whole protein was determined by Bradford assay. The whole protein was diluted to the same concentration using the lysis buffer, and $500 \mathrm{ng}$ of whole protein was incubated with a mixture of reaction buffer containing $20 \mathrm{mM}$ Tris- $\mathrm{HCl}(\mathrm{pH} 8.3), 1.5 \mathrm{mM} \mathrm{MgCl}_{2}, 63 \mathrm{mM} \mathrm{KCl}, 0.05 \%$ Tween 20 and 1 mM EGTA, $0.5 \mu \mathrm{M}$ of TS primer, and $50 \mu \mathrm{M}$ of dNTPs at $30^{\circ} \mathrm{C}$ for $20 \mathrm{~min}$ and $95^{\circ} \mathrm{C}$ for 2 min for inactivation. As a control reaction, the same volume of lysis buffer was incubated with the mixture. After the telomere elongation reaction, the samples were subjected to purification using a Qiagen nucleotide removal kit (\#28304) because impurity including compounds in cell lysates can inhibit PCR reaction, ${ }^{67}$ The purified samples were completely dried and resuspended with $30 \mu \mathrm{L}$ of nuclease-free water. For PCR reaction, 1/10 volume of sample was incubated with a mixture of PCR master mix (Thermo Fisher), 0.125 $\mathrm{U} / \mu \mathrm{L}$ Taq DNA polymerase, $62.5 \mathrm{nM}$ TS primer, $62.5 \mathrm{nM}$ ACX primer, and 5 ag of internal standard control (ITAS) in $20 \mu \mathrm{L}$. The mixture was initially incubated at $95^{\circ} \mathrm{C}$ for $3 \mathrm{~min}$ and then followed by 32 cycles of $95{ }^{\circ} \mathrm{C}$ for $30 \mathrm{~s}, 61^{\circ} \mathrm{C}$ for $30 \mathrm{~s}$, and $72{ }^{\circ} \mathrm{C}$ for $30 \mathrm{~s}$. The PCR products were subjected to $10 \%$ Native-PAGE and then stained by SYBR Gold for detection by Bio-Rad Pharos FX. For preparation of ITAS, myogenin $108 \mathrm{nt}$ (Patent, application number US08/423,403) with partial TS and ACX sequence was initially amplified using TS and ACX primers to generate $156 \mathrm{bp}$ dsDNA and then purified by gel extraction. 
Telomere length assay. MCF7, NHM-002, WM266-4, and UACC-903 cells were treated with DMSO, GTC365 for 5-10 days, or BRACO-19 for 25-30 days. Meanwhile, cells were subcultured to maintain $<90 \%$ confluency. Cells were collected by cell scraper and then subjected to gDNA extraction by DNA extraction kit (Qiagen). Ten ng of gDNA was used for SYBR Green I-based qPCR assay with $1 \mathrm{M}$ betaine, $700 \mathrm{nM}$ telomere primers, and $200 \mathrm{nM} 36 \mathrm{~B} 4$ single-copy gene. The primer sequences used for PCR are shown in Table S3. ${ }^{68}$ A pair of Tel1 and Tel2 primers was used for amplification of the telomere region and a pair of 36B4F and 36B4R primers for amplification of a single-copy gene to normalize data. The PCR was initiated at $95{ }^{\circ} \mathrm{C}$ for $3 \mathrm{~min}$ and then 27 cycles at $95^{\circ} \mathrm{C}$ for $3 \mathrm{~s}$ and $60^{\circ} \mathrm{C}$ for $2 \mathrm{~min}$. The fluorescence signal at $60{ }^{\circ} \mathrm{C}$ was acquired. Triplicate data were averaged and normalized to $36 \mathrm{~B} 4$ to obtain $\Delta \mathrm{Ct}$. The relative telomere length was determined compared to the DMSO.

Senescence $\beta$-galactosidase assay. A colorimetric $\beta$-galactosidase assay was performed according to the protocol. ${ }^{69}$ Briefly, compound-treated MCF7 cells were fixed in $2 \%$ formaldehyde and $0.2 \%$ glutaraldehyde for $5 \mathrm{~min}$ at room temperature. Fixed cells were incubated with staining solution containing $40 \mathrm{mM}$ citric acid (pH 6.0), $5 \mathrm{mM}$ potassium ferrocyanide, $5 \mathrm{mM}$ potassium ferricyanide, 150 $\mathrm{mM} \mathrm{NaCl}, 2 \mathrm{mM} \mathrm{MgCl}$, and $1 \mathrm{mg} / \mathrm{mL}$ X-gal (Fermentas R0401) for $7 \mathrm{~h}$ at $37^{\circ} \mathrm{C}$. Stained cells were washed with D-PBS and methanol and subsequently dried in air.

Immunofluorescence. GTC365-treated MCF7 cells on coverslip were fixed in 2\% paraformaldehyde in PBS for $10 \mathrm{~min}$ at room temperature and then subjected to permeabilization with $0.2 \%$ Triton X-100 in PBS for 10 min at room temperature. Cells were blocked with 4\% BSA and $1 \%$ non-fat milk in PBS for 1 $h$ at room temperature and then incubated with $\alpha$-tubulin against mouse (1:200, Cell Signaling \#3873, $\mathrm{mAb})$ in $20 \%$ blocking solution for $1 \mathrm{~h}$. Afterward, cells were treated with secondary antibodies (1:1000, goat-anti mouse DyLight ${ }^{\circledR} 488$ conjugate) in $20 \%$ blocking solution for $1 \mathrm{~h}$. Following three washings with PBS, slides were mounted in ProLong Gold Antifade solution with DAPI (Life Technologies 
\#P36931). Images were acquired using an Olympus IX71/DP70 digital microscope camera with blue and green filters and then processed with Image Studio Lite (LI-COR Biosciences) and ImageJ.

Annexin V binding assay. GTC365-treated MCF7 cells were trypsinized and washed with cold D-PBS twice. Cells were incubated with Annexin V, Alexa Fluor ${ }^{\circledR} 488$ (Thermo Fisher, A13201), and 7AAD (BD Biosciences, 559925) in a binding buffer (10 mM HEPES pH 7.4, $0.75 \mathrm{mM} \mathrm{MgCl2,} 4 \mathrm{mM} \mathrm{KCl,} 140$ $\mathrm{mM} \mathrm{NaCl}$ and $2.5 \mathrm{mM} \mathrm{CaCl}_{2}$ (http://www.cyto.purdue.edu/cdroms/cyto10a/educationandresearch/annexin.html) at room temperature for 15 min and kept on ice before FACS analysis (FACScanto II, BD Biosciences) in $1 \mathrm{~h}$ at maximum. Data were corrected using control samples including Annexin V, Alexa Fluor® 488 alone, or 7AAD alone.

Caspase assay. MCF7 cells in a 6-well plate were treated with GTC365 for $48 \mathrm{~h}$. The caspase-3/7 assay was conducted using DEVD-AFC as a substrate of capase-3/7. Cells were washed by cold D-PBS and then collected by cell scraper. Cells were lysed with a lysis buffer (Clontech) and incubated 10 min on ice. The supernatant of cell lysate was obtained by centrifugation at $14000 \mathrm{rpm}$ for $20 \mathrm{~min}$. For normalization, the concentration of whole protein was determined by Bradford assay. The cell lysate was incubated with $50 \mu \mathrm{M}$ DEVD-AFC in a reaction buffer (20 mM HEPES pH7.4, $100 \mathrm{mM} \mathrm{NaCl}, 1 \mathrm{mM}$ EDTA, $0.1 \%$ CHAPS, $10 \%$ glycerol, and $10 \mathrm{mM}$ DTT) for $2-3 \mathrm{~h}$ at $37^{\circ} \mathrm{C}$. Fluorescence intensity of released AFC was measured using a BioTek Synergy HT with excitation at $400 \mathrm{~nm}$ and emission at 505 $\mathrm{nm}$. The caspase activity was normalized to the concentration of the whole protein, and the relative caspase-3/7 (DEVDase) activity compared to the DMSO was obtained.

Cell cycle analysis by PI staining. MCF7 cells were treated with GTC365 for 48 h. Cells were trypsinized and washed with cold D-PBS. Cell pellets were subjected to $70 \% \mathrm{EtOH}$ fixation at $-20{ }^{\circ} \mathrm{C}$ 
overnight. Cells were incubated with RNase A and PI for $3 \mathrm{~h}$ at $37^{\circ} \mathrm{C}$ and then kept in ice before FACS analysis (FACScanto II, BD Biosciences, San Jose, CA).

Counting of live cells treated with GTC365. MCF7 cells were treated with DMSO or $0.5 \mu \mathrm{M}$ of GTC365. Cells were trypsinized and then subjected to trypan blue exclusion staining for counting of live cells using microscopy every three days. Afterward, $70 \%$ of cells were recultured with fresh media and DMSO or GTC365. Relative cell numbers compared to the DMSO were obtained.

CellTiter-Glo® viability assay. NHM-002, MCF7, WM266-4, and UACC-903 cells were treated with DMSO or $5 \mu \mathrm{M}$ GTC365. At 120 h CellTiter-Glo® (Promega, Cat No. G7570) was added to wells, and luminescence was read on a FlexStation ${ }^{\circledR} 3$ microplate reader (Molecular Devices). Relative luminescence compared to DMSO was obtained.

\section{RESULTS}

hTERT promoter mutants produce dramatic disruption of the folding of the 5-12 G-quadruplex. There are eight runs of three or four consecutive guanines (G-tracts) in the 5-12 G quadruplex (Figure 1C). Somatic mutations of the hTERT core promoter region are found in G-tracts 5, 7, and 8 (Figure 1, B and C). ${ }^{41}$ Results from DMS footprinting of the full-length (1-12) oligomer show that positions -124 and -125 are located in G-tract 5 (G-quadruplex scaffold and adjacent base), -138 and -139 are in G-tract 7 (hairpin stem), and -146 is in G-tract 8 (hairpin loop). ${ }^{41}$ To determine the effect of these mutations on the G-quadruplex structure, circular dichroism (CD) and DMS footprinting experiments were initially performed. $\mathrm{CD}$ is commonly used to infer the presence as well as the topological state of the Gquadruplex. CD showed that the topological state of mutations in both the 1-12 (full length) and 5-12 Grich strands were similar to the WT. The G124/125A and G138/139A mutants both showed a modest decrease in CD spectra readings, indicating that the G146A mutant was less disruptive than the other 
mutations (Figure S2). The full-length and 5-12 fragments of G124/125A had melting temperatures $\left(T_{\mathrm{m}} \mathrm{s}\right)$ decreased by $1.9^{\circ} \mathrm{C}$ and $4.3{ }^{\circ} \mathrm{C}$ respectively, and G138/139A showed a similar decrease in $T_{\mathrm{m}}$ of $2.0^{\circ} \mathrm{C}$ and $3.4{ }^{\circ} \mathrm{C}$ respectively (Figure $2 \mathrm{~A}$ ). On the other hand, $T_{\mathrm{m}} \mathrm{s}$ of G124A and G146A show a smaller decrease $\left(1.5-1.6^{\circ} \mathrm{C}\right.$ and $\left.0.9-1.6^{\circ} \mathrm{C}\right)$ compared to G124/125A and G138/139A (Figure 2A). These modest decreases in $T_{\mathrm{m}} \mathrm{s}$ suggested that additional factors beyond the destabilization of the G-quadruplex, such as change in folding or unfolding pathways, could be responsible for overexpression of hTERT. The single molecule laser tweezers experiments suggested that the 26-base hairpin in the 5-12 G-quadruplex plays a pivotal role in the cooperative folding process needed to form a fully folded functional repressor. On the basis of these results, G138/139A and G146A mutations are the most likely to change the folding pattern of the WT structure. Figure 2B shows that WT G-tracts 5, 6, 11, and 12 were protected from DMS cleavage, which is consistent with previous results. ${ }^{41}$ Significantly, all the mutants showed changes in DMS footprinting patterns in comparison to the WT. The G124/G125A mutant showed the greatest changes in DMS protection pattern, with a loss of protection of G-tracts 7, 9, and 10. In addition, the G124A, G138/139A, and G146A mutants showed more subtle changes in the cleavage of G-tracts in the stem loop, which may represent conformational changes in this part of the structure. The stem loop mutations (G138/139A and G146A) also showed increased cleavage of G-tract 6, suggesting a major change in the folding pattern.

To further understand the influence of the G124/125A mutation on the 5-12 region, we carried out single-molecule experiments on a DNA construct that contains these mutations. We used double-stranded DNA in conditions to allow the formation of only G-quadruplex structures. ${ }^{58}$ Given that the $44-n t 5-12$ region contains eight G-rich tracts, multiple G-quadruplex populations can exist, each requiring a minimum of four G-rich tracts. Together with partially folded structures ${ }^{42}$ this constitutes a rather complex array of observable structures in single-molecule mechanical unfolding experiments. Using an approach we have recently established to follow the population dynamics of individual DNA secondary structures with the statistical method PoDNano (Population Deconvolution at Nanometer resolution), ${ }^{58,70}$ we first identified the size of different populations (measured in change in contour length $[\Delta L]$; see 

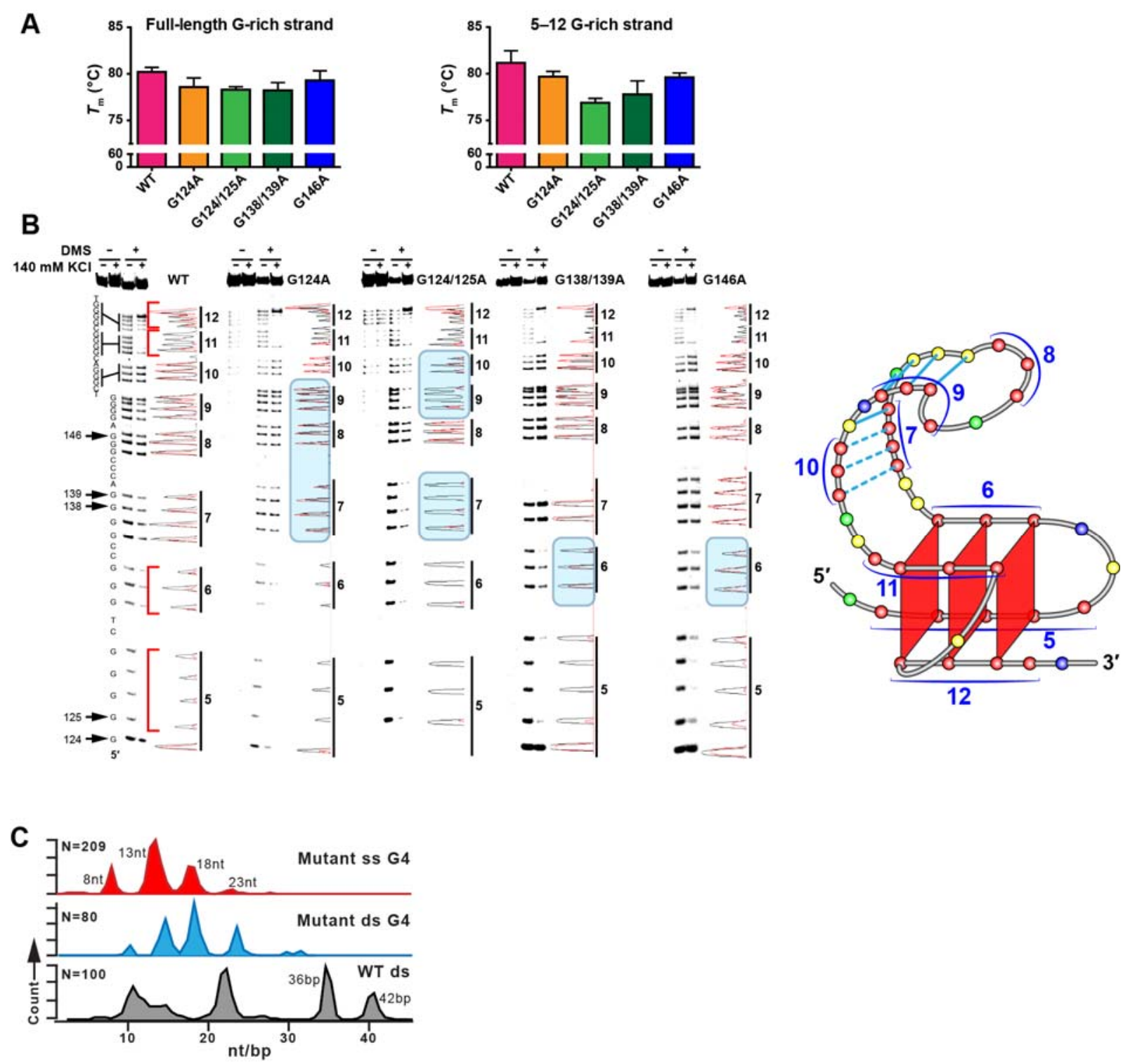

Figure 2. Biophysical and biochemical characterization of the full-length and 5-12 G-quadruplexes in the hTERT promoter harboring the somatic G-to-A mutations in comparison to the WT sequence. (A) $T_{\mathrm{m}}$ of the full-length (left) and 5-12 (right) strands with WT and mutants. (B) DMS footprinting shows the effect of somatic mutations on the folding topology of the 5-12 G-quadruplex. The blue boxes highlight the changes in DMS footprinting patterns in G-tracts 6 through 10 of the different mutants. The red brackets show the protection of G-tracts 1,2,11, and 12 in the WT. The 5-12 G-quadruplex with the positions of the G-tracts is shown to the right. (C) Different populations of folded species (G4 = Gquadruplex) in single-stranded (ss; red) and double-stranded (ds; blue) G124/125A mutants. The gray trace shows the population pattern of the double-stranded WT 5-12 G-quadruplex sequence. N represents the total number of force-extension $(\mathrm{F}-\mathrm{X})$ curves collected by the mechanical unfolding method $(\mathrm{nt} / \mathrm{bp}=$ nucleotides/base pairs). 
Methods) and their percentages of formation. As shown in Figure 2C, the G124/125A mutations dramatically change the population pattern of G-rich structures, especially for the large species (36 bp and $42 \mathrm{bp}$ ), in both single-stranded and double-stranded 5-12 fragments. These large species are likely fully folded G-quadruplexes (42 bp) and their associated intermediates (36 bp). In addition, the overall formation percentage of G-rich species is reduced compared to the WT DNA (Figure 2C). At first pass, the minimal effects observed by $\mathrm{CD}\left(1.9-4.3^{\circ} \mathrm{C}\right)$ seem incompatible with the far more dramatic changes suggested by footprinting and single-molecule experiments. This apparent discrepancy can be rationalized once it is recognized that different features are being measured by the three different techniques. Footprinting experiments are sensitive to the precise G-tracts that are being utilized in the formation of the G-quadruplex structures, and the single-molecule experiments are sensitive to the precise contour length of the different species present and can discern small percentages of different species. $\mathrm{CD}$, on the other hand, is measuring the absorption of the G-quadruplex, and while this may change with the folding pattern, if the basic folding pattern remains the same, CD may not be sensitive to using different G-tracts or having different contour lengths.

\section{Identification of a compound that restores cooperative folding in mutant hTERT promoters.}

Since the G124/125A mutant leads to a dramatic shift in the folded population to smaller species (Figure 2C), and the other mutants in the hairpin loop change the DMS protection pattern (Figure 2B), this suggested the involvement of the folding of the 5-12 G-quadruplex in the loss of hTERT transcriptional silencing. The absence of mutations in the 1-4 1:3:1 G-quadruplex (Figure 1C) also supports this premise. We designed a medium-throughput assay based on a well-established FRET assay ${ }^{71}$ to screen for compounds that might act as chaperones at the early stage of the folding process to shift the population species of the mutants in the 5-12 G-quadruplex back to the larger species. The WT strand containing the 5-12 G-quadruplex was labeled with FAM and TAMRA at each end for the FRET assay. When the Gquadruplex is folded, two fluorophores are in proximity, which leads to a decrease in FAM fluorescence (Figure 3A). The system was established so that there would be an equilibrium between the folded and 

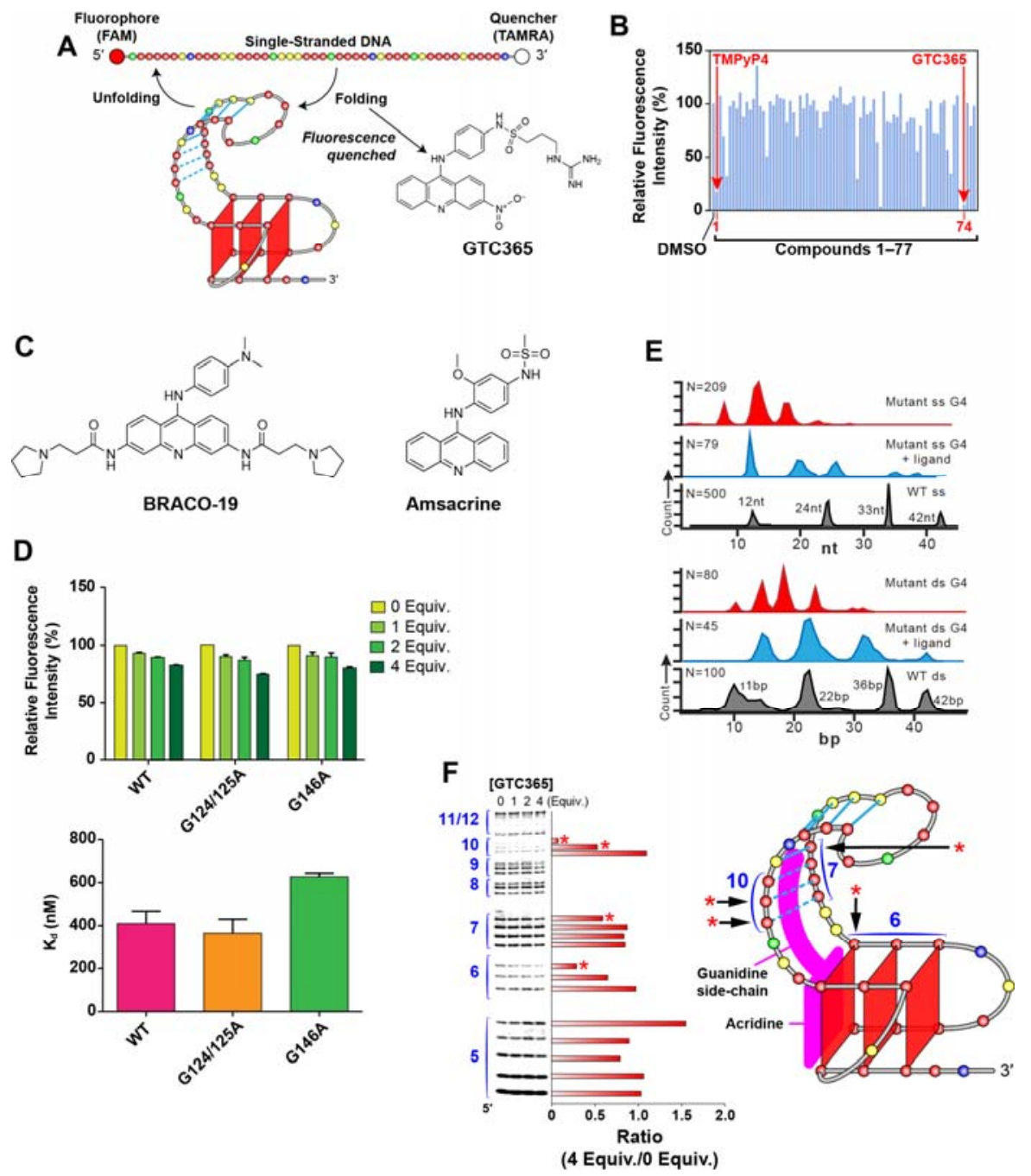

Figure 3. Identification by FRET screening of GTC365 and characterization of its interaction with the 512 G-quadruplex. (A) Principle of compound screening by FRET assay. The ends of the 5-12 G-tract were labeled with FAM $\left(5^{\prime}\right)$ and TAMRA ( $\left.3^{\prime}\right)$, which upon drug-binding brings each end of the oligomer closer. Subsequently, FAM fluorescence is quenched by TAMRA. (B) Representative result from a plate using medium-throughput screening with the NCI Diversity Set. The chemical structure of GTC365 is shown in (A). As a positive control, TMPyP4, a well-known G-quadruplex binder, decreased fluorescence intensity at $520 \mathrm{~nm}$ by $82 \%$. (C) Chemical structures of BRACO-19 and Amsacrine. (D) GTC365 dose dependence FRET changes for WT, G124/125A, and G146A (top) and binding affinity ( $\mathrm{K}_{\mathrm{d}}$ values) with GTC365 using the FRET assay (bottom). (E) Different populations of G-quadruplex (G4) in singlestranded (top) and double-stranded (bottom) G124/125A mutants in the presence of $2 \mu \mathrm{M}$ GTC365. N represents the total number of F-X curves collected by the mechanical unfolding method (nt = nucleotides; $b p=$ base pairs). (F) Determination of location of the GTC365 binding site on the WT 5-12 G-quadruplex using DMS footprinting. The results of the comparison of the protection to DMS cleavage in the absence and presence of 4 equiv. of GTC365 are shown to the right of the gel, and their locations in the 5-12 G-quadruplex are shown in the right panel. The right panel also shows the inferred location of the GTC365 molecule (purple) relative to the G-quadruplex and hairpin loop. The arrows with asterisks indicate bases that are protected from DMS in the presence of GTC365. 
unfolded states. Using this oligomer, the NCI Diversity Set III ( $\sim 1500$ compounds) was subjected to the FRET assay. A representative plate from the screening is shown in Figure 3B. Forty-five compounds from the NCI Diversity Set decreased the fluorescence intensity by at least $50 \%$ (data not shown), including GTC365 (NSC177365) (Figure 3A), which showed a very significant reduction of fluorescence intensity (94\%). GTC365 was selected to move forward with because it is a compound with an acridine scaffold similar to the telomeric G-quadruplex-binding compound BRACO-19 as well as Amsacrine (Figure 3C). Amsacrine is a topoisomerase II inhibitor used to treat acute lymphocytic leukemia, ${ }^{72}$ and BRACO-19 is a G-quadruplex-interactive compound that produces telomere shortening by binding to the telomeric G-quadruplexes, resulting in cellular senescence and cessation of growth after 15 days. ${ }^{73}$ GTC365 showed a dose-dependent decrease in fluorescence intensity of the WT, G124/125A, and G146A probes to a similar extent (Figure 3D). $\mathrm{K}_{\mathrm{d}}$ values showed that GTC365 preferentially bound to the WT and G124/125A with a similar binding affinity ( $400 \mathrm{nM})$, in contrast to G146A, which showed a 1.5fold higher $\mathrm{K}_{\mathrm{d}}$ value (Figure 3D). Our observation that GTC365 binds as strongly to the WT as the G124/125A mutant and reduces the fluorescence intensity to the same extent as the mutants suggests that this compound will be equally active in refolding the G-quadruplex in WT cells as in those carrying mutations.

To determine the effects of GTC365 on the thermal stability of the WT and the mutant Gquadruplexes, $T_{\mathrm{m}} \mathrm{s}$ were determined by CD (Figure S3). GTC365 dose-dependently increased the $\Delta T_{\mathrm{m}}$ of the WT G-quadruplex by $12.9^{\circ} \mathrm{C}$ at 2 equiv. The $T_{\mathrm{m}} \mathrm{S}$ of the G124/125A, G138/139A, and G146A mutants were more significantly increased by $4-7{ }^{\circ} \mathrm{C}$ compared to the WT, while that of G124A was similar to the WT at 2 equiv. There was little change in $T_{\mathrm{m}}$ for the i-motif formed from the full-length Crich strand by GTC365 (Figure S4), suggesting that GTC365 selectively binds to the G-quadruplex over the i-motif.

Single-molecule experiments were used to determine the ability of GTC365 to reverse the effect of the G124/125A mutant on the hTERT G-quadruplex folding process. After the G124/125A mutant was incubated with GTC365 under conditions in which the formation of a G-quadruplex over an i-motif is 
favored, we observed recovery of the full-length G-rich species ( $>36 \mathrm{nt} / \mathrm{bp})$ in both the single-stranded and the double-stranded templates with a markedly greater recovery in the double-stranded template (Figure 3E).

To gain insight into where GTC365 binds to the 5-12 G-quadruplex, we examined the effect of drug binding on the DMS footprint of the WT G-quadruplex-forming sequence. As shown in Figure 3F (left panel), GTC365 protected a guanine in the $5^{\prime}$-tetrad of G-tract 6 as well as select bases at the $3^{\prime}$-ends in the $\mathrm{G}-\mathrm{C}$ and $\mathrm{G}-\mathrm{G}$ base pairing between $\mathrm{G}$-tracts 7 and 10 in the hairpin stem (asterisks and arrows in left and right panels). These data suggest that the acridine moiety is positioned on the $5^{\prime} \mathrm{G}$-tetrad and the guanidine side-chain interacts with the four $\mathrm{G}-\mathrm{C}$ and $\mathrm{G}-\mathrm{G}$ base pairs formed by G-tracts 7 and 10 (Figure $3 \mathrm{~F}$, right panel). It is well known that the guanidinium group of arginine binds to guanines in the major groove of duplex DNA, ${ }^{74}$ supporting the idea that the guanidine group of GTC365 binds to the hairpin duplex while the acridine moiety is stacked on the $5^{\prime}$ G-tetrad, as shown in Figure 3F. This proposed model for how GTC365 binds to the 5-12 G-quadruplex explains both the stabilization and chaperone effect on the folding of the 5-12 G-quadruplex attributed to the acridine and guanidine groups respectively. Nevertheless, this model remains tentative until further SAR or structural studies provide firm evidence of the binding mode. To gain further insight into the differences that would result from a chaperone effect associated with the propylguanidino group of GTC365 and a compound lacking this moiety, we compared the biochemical effects of GTC365 with BRACO-19, which lacks this chemical moiety.

\section{GTC365 works directly through the hTERT promoter to lower hTERT and BCL2.}

The E-box in the hTERT core promoter is a critical element for transcription of hTERT and recruits various transcription factors, such as MYC and the upstream stimulatory factors Mad1 and MAX. ${ }^{75}$ Since MYC is an oncogene with a G-quadruplex structure in the promoter region, ${ }^{34,76}$ it was important to determine whether GTC365 effects the repression of hTERT promoter activity directly by binding to the hTERT promoter G-quadruplex or by indirectly modulating MYC transcription through the MYC 
promoter G-quadruplex. To distinguish between these possibilities, two constructs were prepared, the first being the pGL3-WT plasmid encoding luciferase as a reporter gene and contains the 360 base-pair hTERT promoter region including the upstream E-box (CACGTG) and the core region, and the second (pGL3-E-box mutant) being the same plasmid but with a E-box mutation (TTTGTG. After transfection into MCF7 cells, which are known to be hTERT-positive because the core promoter is activated, the luciferase activities of the two plasmids were determined following treatment with GTC365. As shown in Figure 4A (left panel), GTC365 showed a similar dose-dependent decrease of luciferase activity in both the WT and E-box Mut constructs, indicating that GTC365 does not act via the E-box. In contrast, BRACO-19 decreased luciferase activity in the WT but failed to reduce luciferase activity in the E-box Mut construct (Figure 4A, right panel). Therefore, BRACO-19 most likely downregulates hTERT indirectly through repression of MYC by potentially binding to the MYC G-quadruplex, whereas GTC365 acts directly through the hTERT promoter.

Given that hTERT is known to alter expression of various genes important for cancer cell survival, ${ }^{77,78}$ we also sought to evaluate the specificity of GTC365-mediated hTERT repression for modulation of these effects. BCL2, which encodes an anti-apoptotic protein, is one such primary downstream target that is activated by hTERT to repress apoptosis. ${ }^{15}$ Notably, siRNA-mediated hTERT knockdown has been shown to repress BCL2 transcription, leading to apoptotic cell death. ${ }^{79,80}$ To define the effect of GTC365 on the transcription of hTERT and its downstream targets, the relative mRNA levels of MYC and BCL2 were determined by quantitative reverse transcriptase PCR analysis in MCF7 cells after treatment with GTC365 for $72 \mathrm{~h}$. As shown in Figure 4B (left panel), GTC365 decreased the hTERT mRNA levels in a dose-dependent manner by up to $57 \%$ at $1 \mu \mathrm{M}$, and BCL2 mRNA levels were also dose-dependently decreased by up to $18 \%$ at $1 \mu \mathrm{M}$, with no significant change in MYC mRNA levels. In contrast, BRACO-19 decreased mRNA levels of both hTERT and MYC to a similar extent at a somewhat higher concentration range compared to GTC365 but, as expected, had no effect on BCL2 mRNA expression (Figure 4B, right panel). Therefore GTC365, in contrast to BRACO-19, is unique in that it directly repressed the transcription of hTERT, which then led to a downstream decrease of BCL2 

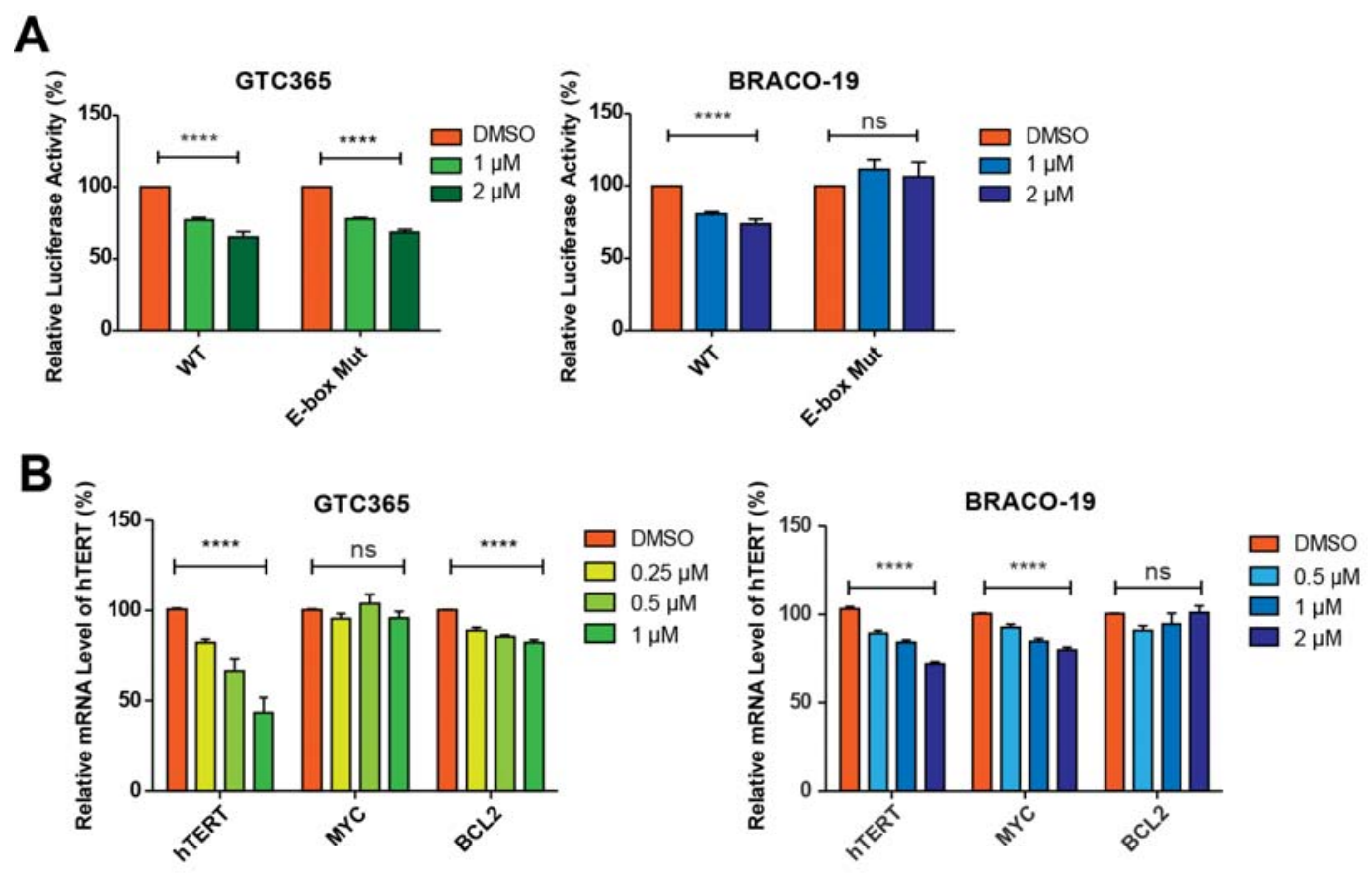

C

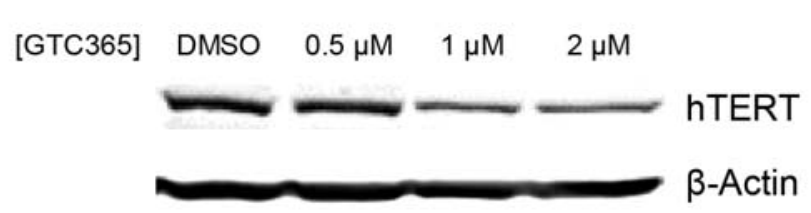

\section{E}
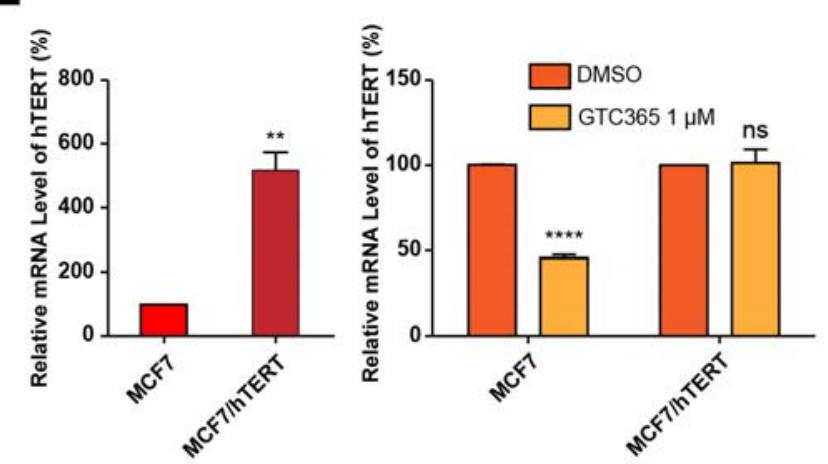

D

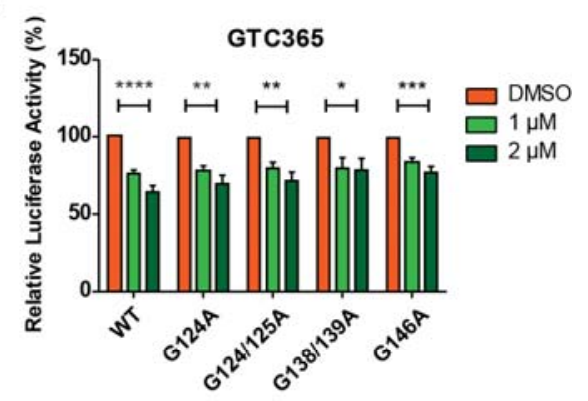

Figure 4. GTC 365 acts directly through the hTERT core promoter to suppress hTERT transcription through a different mechanism than BRACO-19. (A) GTC365 produces direct downregulation of the hTERT core promoter (left panel), while BRACO-19 downregulation of hTERT is mediated via the MYC-binding E-Box (right panel) (ns = not significant). E-box Mut is a pGL3 construct with mutation of the MYC binding site on the hTERT promoter. (B) GTC365 produces direct repression of hTERT transcription and the downstream molecule BCL2 but has no effect on MYC mRNA level (left panel). In contrast, BRACO-19 represses MYC and hTERT transcription and has no significant effect on BCL2 mRNA levels in MCF7 cells after $72 \mathrm{~h}$ (right panel). Reverse transcription and qPCR were performed to quantitate the relative mRNA levels of hTERT, MYC, and BCL2 to GAPDH. (C) Decreased expression of hTERT protein after treatment with GTC365. MCF7 cells were treated with GTC365 for $72 \mathrm{~h}$, and the cell supernatant was subjected to immunoblot analysis using hTERT and $\beta$-actin antibodies as a loading control. (D) Dose-dependent decrease of hTERT core promoter activity by GTC365. MCF7 cells were 
transfected with pGL3 constructs and pRL-TK for $6 \mathrm{~h}$ and then treated with GTC365 for $24 \mathrm{~h}$. A dual luciferase assay was performed to obtain luciferase activity of firefly and renilla for normalization. (E) GTC365 directly targets the hTERT promoter to downregulate transcription. MCF7 cells and a stable cell line overexpressing ectopic hTERT mRNA through the CMV promoter (left panel) were treated with 1 $\mu \mathrm{M}$ of GTC365 for $72 \mathrm{~h}$ and then subjected to reverse transcription and qPCR to measure the effect of GTC365 on the mRNA level of hTERT (right panel). P values $\left(* \mathrm{P}<0.1, * * \mathrm{P}<0.01,{ }^{*} * * \mathrm{P}<0.001\right.$, $* * * * \mathrm{P}<0.0001)$ were obtained by one-way ANOVA analysis for (A), (B), (D), and (E). 
expression. It was demonstrated by immunoblot analysis that the protein level of hTERT was also downregulated by GTC365 (Figure 4C). The unique effect of GTC365 on hTERT and BCL2 expression in contrast to BRACO-19 can be attributed to the interaction of the guanidine side chain in GTC365 with the 26-base hairpin loop (Figure 3F, right panel), which acts as a chaperone at an early step in facilitating the folding of the silencer element. The effect of GTC365 on the activity of the promoter with somatic mutations was also examined by transfecting MCF7 cells with pGL3 constructs containing both the mutations and the WT. As shown in Figure 4D, GTC365 decreased luciferase activity of the mutants in a dose-dependent manner and therefore acts broadly to downregulate hTERT promoter activity in the WT and mutants.

To assess directly whether GTC365 mediates its effects through the hTERT promoter element, we compared the effect of GTC365 on hTERT transcription in MCF7 cells versus similar cells containing a plasmid that overexpresses hTERT, but under the control of the CMV promoter. The results show that while GTC365 has a significant effect on hTERT transcription in the MCF7 control cells, where the hTERT promoter is targeted, there was no effect on hTERT transcription in the MCF7 cell line transfected with the plasmid that overexpresses hTERT (Figure 4E). The results of this experiment strongly suggest that the molecular target for GTC365 is at the core promoter level rather than a downstream event.

\section{GTC365 has a more potent effect on telomerase, telomere shortening, and senescence than BRACO-19.}

We used hTERT-positive MCF7 breast cancer cell lines ${ }^{81}$ to gain mechanistic insight into how the GTC365-induced inhibition of proliferation occurs. In order to determine whether GTC365's effects are mediated primarily through telomeric G-quadruplex inhibition or through hTERT transcriptional repression, a comparison of the effects of GTC365 and BRACO-19 was done. While both GTC365 and BRACO-19 produced similar extents of stabilization of the hTERT G-quadruplex, BRACO-19 had a much greater effect on stabilization of the telomeric G-quadruplex (Figure S5). However, as shown above 
(Figure 4, A and C), only GTC365 is capable of specifically inhibiting hTERT transcription. Next, a modified TRAP assay ${ }^{67}$ used to compare the effects of GTC365 and BRACO-19 on telomerase activity revealed that GTC365 dose-dependently reduced telomerase activity by $80 \%$ at $2 \mu \mathrm{M}$, whereas BRACO19 reduced telomerase activity by only $40 \%$ at $4 \mu \mathrm{M}$ (Figure 5A). Thus, telomerase activity is much more potently affected by direct transcriptional targeting of hTERT mediated by GTC365 than through targeting of the telomeric G-quadruplexes mediated by BRACO-19.

To further explore the relative effects of GTC365 and BRACO-19, we measured changes in relative telomere length induced by GTC365 and also measured induction of senescence, a known consequence of telomere shortening. ${ }^{82}$ Changes in telomere length were measured by qPCR with gDNA extracted from MCF7 cells incubated with GTC365 and BRACO-19. GTC365 caused both a dose- and time-dependent decrease in telomere length (Figure 5B, left and center respectively). Whereas GTC365 decreased telomere length by $15 \%$ (5 days) and 20\% (10 days) at concentrations as low as $0.5 \mu \mathrm{M}$ (Figure $5 \mathrm{~B}$, center), BRACO-19 showed no significant effect as high as $2 \mu \mathrm{M}$ after 5 days (Figure 5B, right), consistent with prior reports. ${ }^{83}$ Senescence was then assessed according to lysosomal $\beta$-galactosidase overexpression indicated by the presence of indigo (blue dye) due to its catalytic release from X-gal. In addition, cells were assessed for flattened and enlarged morphologic phenotypes characteristic of senescence. As shown in Figure 5C (center panel), the blue-stained MCF7 cells show a distinct senescence-like phenotype, with significant flattening and enlargement following 5-10 days of treatment with $0.5 \mu \mathrm{M}$ GTC365. As anticipated, BRACO-19 had very little effect on these measures of senescence (Figure 5C, right panel).

To evaluate the comparative effects of GTC365 versus BRACO-19 on the cooperative folding process, we carried out two different experiments. First, we compared the distribution of the different populations of small and large species using single-molecule experiments as described previously with GTC365 and BRACO-19 in the G138/139A mutant (Table S1). A comparison of the results of the singlemolecule assays on the single-stranded G138/139A mutant DNA with and without GTC365 or BRACO19 is shown in Figure 5D. Similar to the G124/125A mutant, the population of fully folded structures is 
A
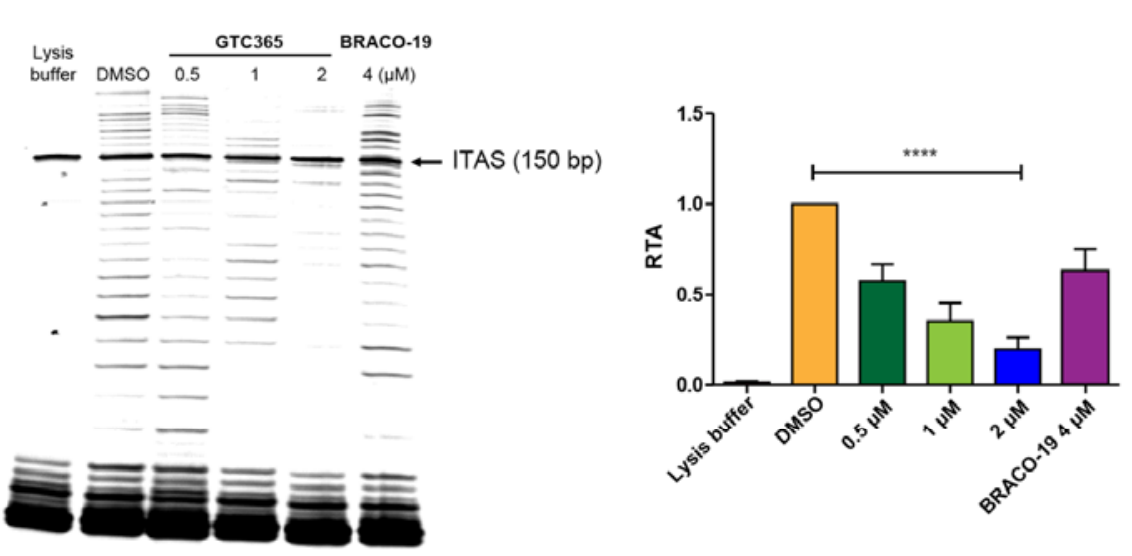

B

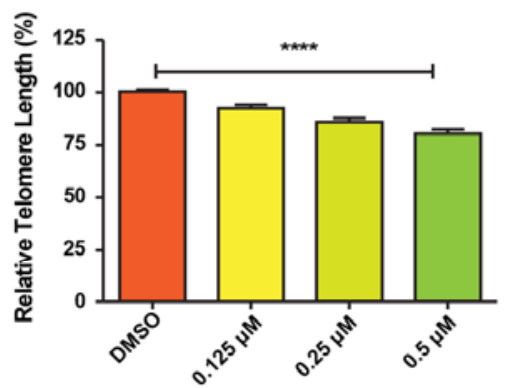

[GTC365]

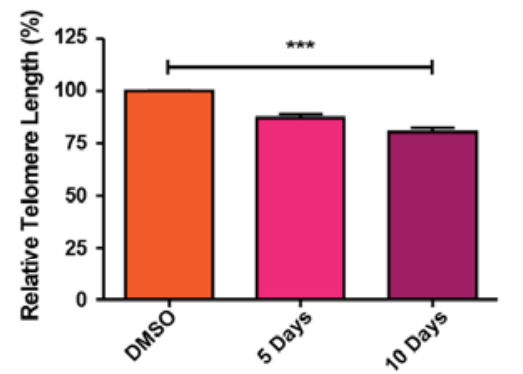

[GTC365]

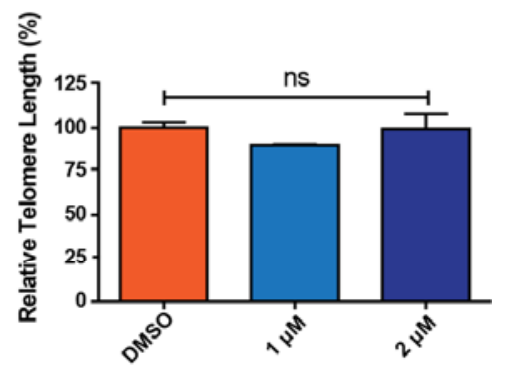

[BRACO-19]

C
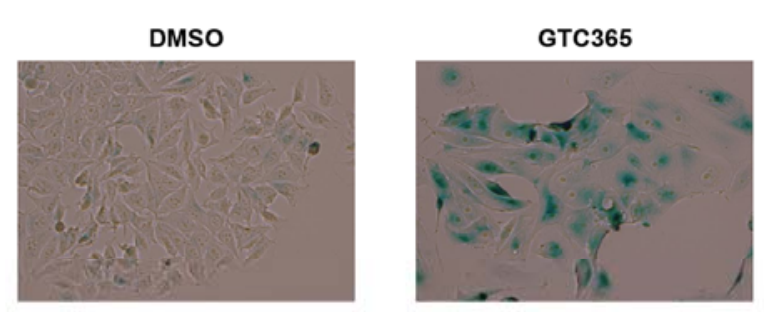

D

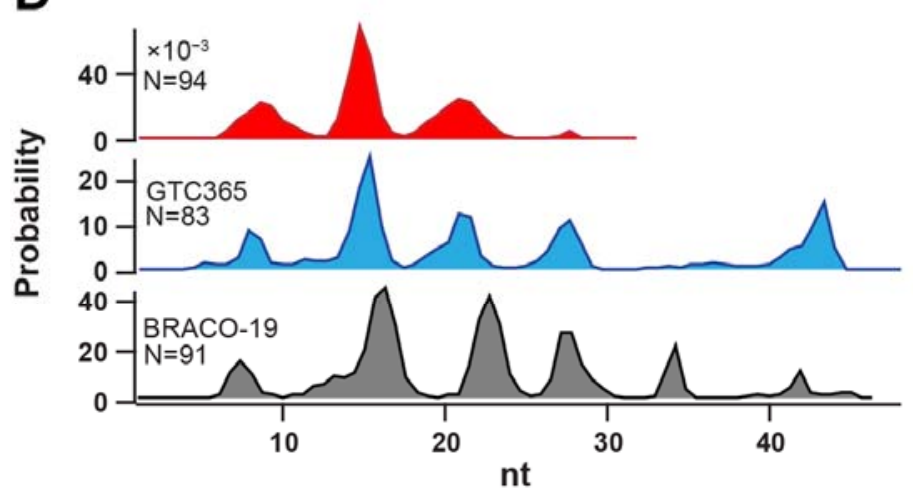

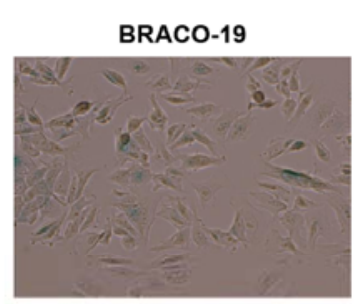

E
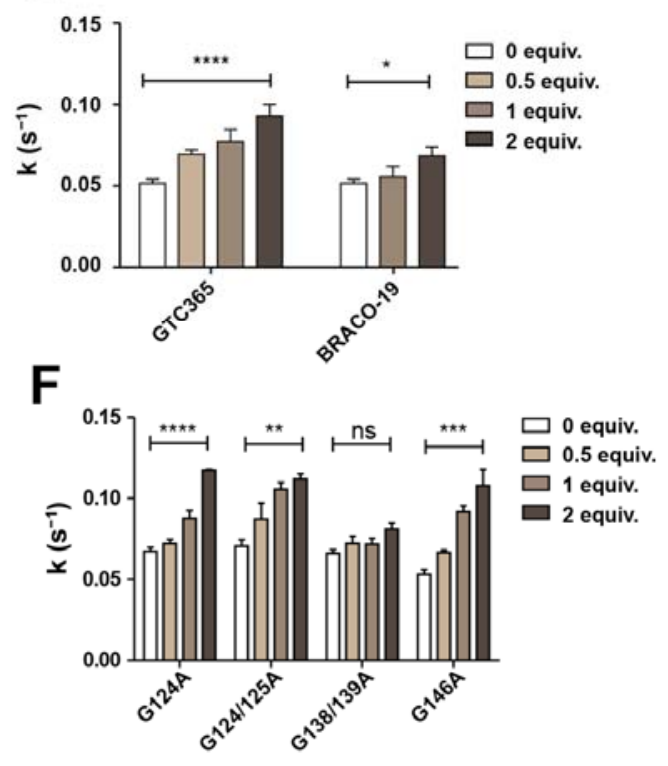
Figure 5. The more potent effect of GTC365 over BRACO-19 on telomerase activity resulting in more rapid telomere shortening and induction of senescence is due to the selective steering of the folding to the more fully folded forms of the 5-12 G-quadruplex by GTC365. (A) GTC365 shows a more potent decrease of telomerase activity than BRACO-19. MCF7 cells were treated with GTC365 and BRACO-19 for $72 \mathrm{~h}$ and then subjected to the modified TRAP assay. Right panel shows a quantitation of the results. Relative telomerase activity (RTA) was determined and compared with the DMSO-treated sample. (B) Dose- and time-dependent loss of telomere length following short-term exposure to GTC365 and BRACO-19. MCF7 cells were treated with different doses of GTC365 for 10 days (left), $0.5 \mu \mathrm{M}$ of GTC365 for 5 or 10 days (center), or different doses of BRACO-19 for 5 days (right). Genomic DNA was extracted and then subjected to qPCR. Ct values of telomeres were normalized to that of 36B4 (single copy gene) to obtain $\Delta \mathrm{Ct}$. (C) Induction of senescence-like phenotype by short-term exposure of GTC365. MCF7 cells were treated with $0.5 \mu \mathrm{M}$ of GTC365 (center) and $2 \mu \mathrm{M}$ of BRACO-19 (right) for 10 days. DMSO served as a control (left). A senescence $\beta$-galactosidase staining assay was performed as described in the Experimental. These images were obtained at the same magnification. (D) Biophysical comparison of the effects of GTC365 and BRACO-19 on populations of the G138/139A mutant hTERT 5-12 G-quadruplex. Top panel red (control), middle panel blue (GTC365), and bottom panel black (BRACO-19). nt and $\mathrm{N}$ as defined in Figure 3E. (E) Comparison of kinetics of initial folding rate of the WT 5-12 G-quadruplex with GTC365 and BRACO19 by temperature-jump method. (F) Enhanced initial folding rate of the 5-12 G-quadruplexes carrying the different hTERT mutants by GTC365. The timecourse CD signal of preheated oligo with compound or DMSO in a buffer containing $10 \mathrm{mM}$ Tris- $\mathrm{HCl}$ (pH 7.5) and $5 \mathrm{mM} \mathrm{KCl}$ was monitored at $262 \mathrm{~nm}$ and $25^{\circ} \mathrm{C}$. The initial folding rate $\mathrm{k}\left(\mathrm{s}^{-1}\right)$ was obtained by one-phase association curve fitting. $\mathrm{P}$ values $\left(* \mathrm{P}<0.1, * * \mathrm{P}<0.01, * * * \mathrm{P}<0.001\right.$, $\left.{ }^{*} * * * \mathrm{P}<0.0001\right)$ for (A), (B), (E), and (F) were obtained by one-way ANOVA analysis. 
small ( $>40 \mathrm{nt}$ species in Figure 5D, top; see Table S1 for detailed population distribution) in the G138/139A mutant without addition of ligand. After incubating with $2 \mu \mathrm{M}$ GTC365, the fully folded structures significantly recovered (18.9\% of all populations; Figure 5D, middle, and Table S1), demonstrating the population effect of this ligand to form the fully folded G-quadruplex species. BRACO-19 minimally promoted the fully folded structure (the population increased to $4.6 \%$; see Table $\mathrm{S} 1$ ); instead, this molecule increased partially folded populations (the $\sim 30 \mathrm{nt}$ species in Figure $5 \mathrm{D}$, bottom). These results provide a rationale for the discrepancy in the biological activities of GTC365 and BRACO-19.

Second, we used CD kinetic analysis to compare the relative rates of initial folding for GTC365 and BRACO-19 in the WT and mutant species with GTC365 (Figure 5, E and F). We then used a temperature-jump method ${ }^{84}$ to compare the initial folding rate of the 5-12 WT G-quadruplex with GTC365 and BRACO-19 using a time-course CD signal curve. A representative kinetics curve of the 512 WT G-quadruplex with GTC365 is shown in Figure S6. As shown in Figure 5E, the initial folding rate of the 5-12 WT G-quadruplex by GTC365 at 2 equiv. was increased from $0.051 \mathrm{~s}^{-1}$ to $0.093 \mathrm{~s}^{-1}$, showing an increase of $0.042 \mathrm{~s}^{-1}$, while BRACO-19 showed a much smaller increase $\left(0.017 \mathrm{~s}^{-1}\right.$ at 2 equiv.). GTC365 also increased the initial folding rates of G124A, G124/125A, and G146A in a dose-dependent manner by $0.049,0.042$, and $0.054 \mathrm{~s}^{-1}$ at 2 equiv., while the effect on the G138/139A mutant was insignificant (Figure 5F). This result was unexpected since the results in Figure 5D show that the populations of the larger folded species are increased by GTC365 in the G138/139A mutant. However, this result may show that GTC365 can have thermodynamic as well as kinetic effects, depending on the state of the initial folded form in each of the different mutants.

\section{GTC365 produces both apoptotic and nonapoptotic cell death in MCF7 cells.}

We have shown that GTC365 leads to telomere shortening and senescence. However, it is also possible that GTC365 could drive apoptosis, given that hTERT siRNA treatment has been shown to result in downregulation of BCL2 and upregulation of $\mathrm{BAX}^{79,85}$ and that a high BAX/BCL2 ratio is one of the 
indicators for apoptosis. ${ }^{86}$ Indeed, we show above that GTC365 represses BCL2 transcription (Figure 4B, left). Therefore, to also explore the capacity of GTC365 to induce apoptosis, we examined the effect of GTC365 on multiple measures of apoptosis, including the BAX/BCL2 ratio, Annexin V staining, Caspase 3/7 activity, and PARP-1 cleavage. We found that GTC365 increased the BAX/BCL2 mRNA ratio in a dose-dependent manner by nearly 3-fold (Figure 6A). Next, we measured GTC365-induced changes in Annexin $\mathrm{V}$ and 7-AAD staining in order to evaluate the extent and stage of apoptosis (Figure 6B). After an initial $24 \mathrm{~h}$ treatment of GTC365, and then a further $48 \mathrm{~h}$ post-treatment incubation, the population of Annexin $\mathrm{V}+/ 7 \mathrm{AAD}$ increased from $1 \%$ to $5 \%$ in a dose-dependent manner (top). There was also a timedependent increase of the Annexin V+/7AAD by 7\% after $120 \mathrm{~h}$ (bottom). Representative cytograms of Annexin V+/7AAD double-staining are shown in Figure S7. Overall, these data suggest that a substantial proportion of cells have undergone apoptosis $120 \mathrm{~h}$ post-GTC365 treatment. The activity of caspase- 3 and caspase-7, key enzymes that drive apoptosis by cleavage of substrates containing the amino acid sequence DEVD, was then measured after treatment with GTC365. Because MCF7 cells lack caspase-3, caspase-7 activity was measured (Figure 6C), and it was found that there was a dose-dependent increase in caspase3/7 (DEVDase) activity (47\% at $0.5 \mu \mathrm{M})$. Finally, we measured PARP-1 cleavage. PARP-1 is a critical molecule for DNA repair whose inactivation by cleavage leads to DNA degradation and cell death, another indicator of apoptosis. ${ }^{87}$ GTC365 showed a dose-dependent increase in the cleaved fragment of PARP-1 (Figure 6D).

In order to comprehensively assess the effects of GTC365 on cellular phenotypes, we also examined its effects on cell cycle progression in MCF7. GTC365 increased the population of G0/G1 (from 57\% to $71 \%$ ) with a corresponding decrease in S-phase population (from 33\% to $10 \%$ ) in a dose-dependent manner after $48 \mathrm{~h}$ treatment (Figure 6E). In addition, there was accumulation of G2/M phases (from 10\% to 19\%). Representative histograms of PI fluorescence are shown in Figure S8. On the basis of the G2/M phase arrest by GTC365, it was inferred that there would be a failure of mitosis or cytokinesis because other functions of hTERT are involved in the regulation of mitosis by localization to mitotic spindles and centromeres ${ }^{88}$ and by tubulin organization. ${ }^{77}$ As anticipated, abnormal phenotypes, such as bridges 

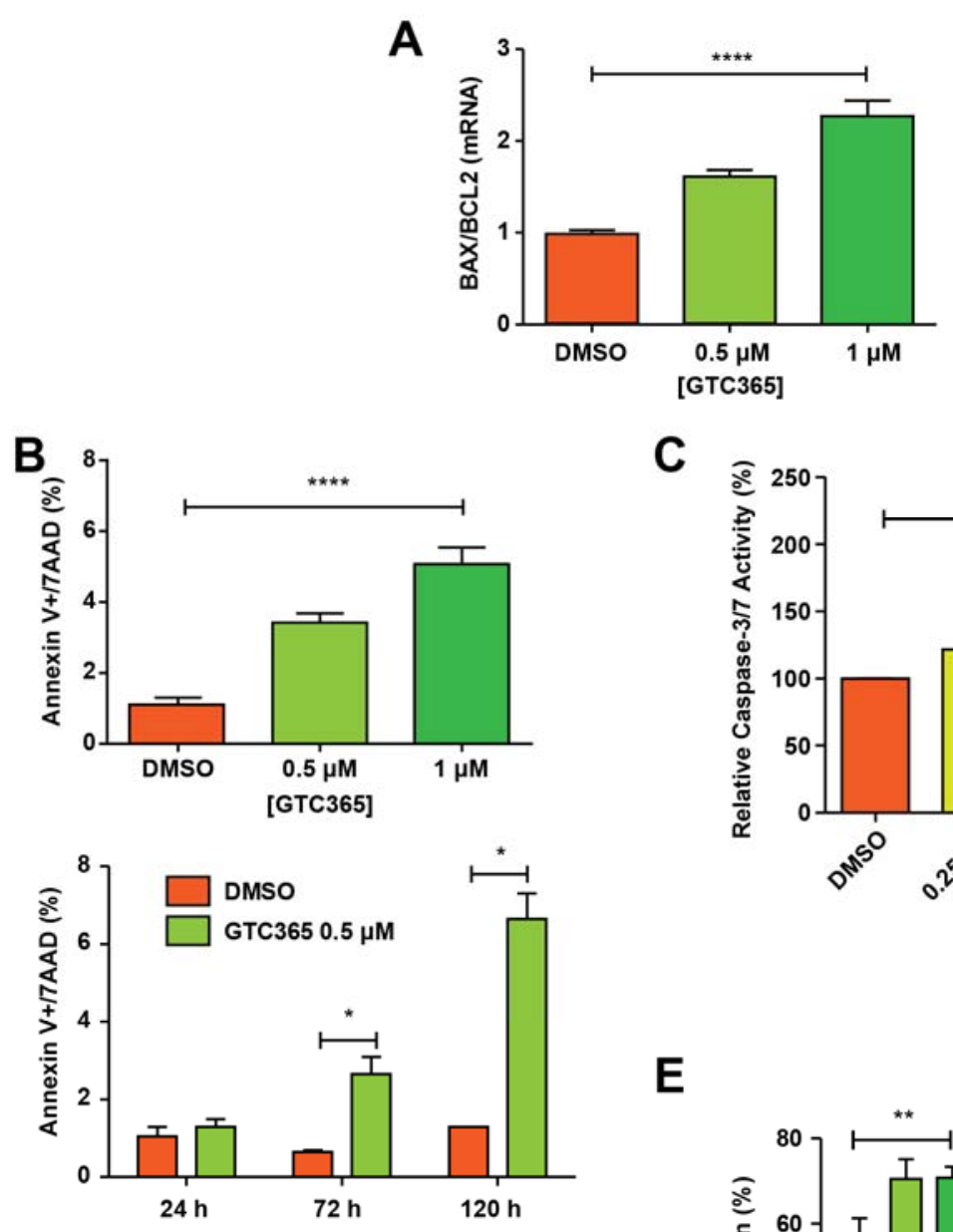

C

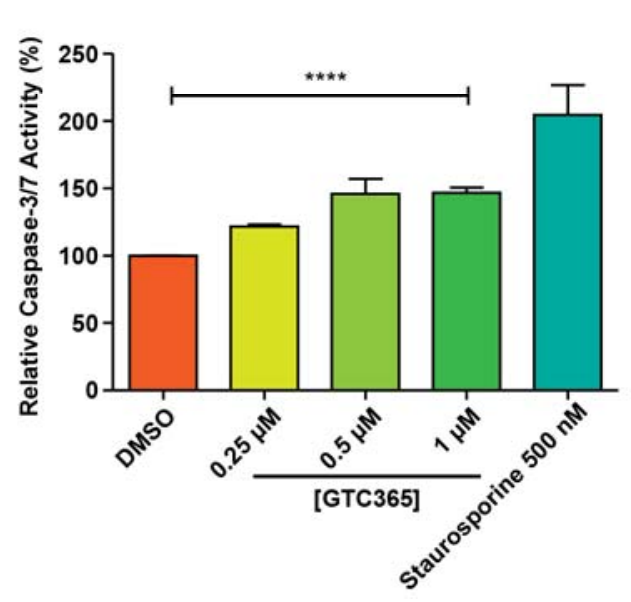

E

D
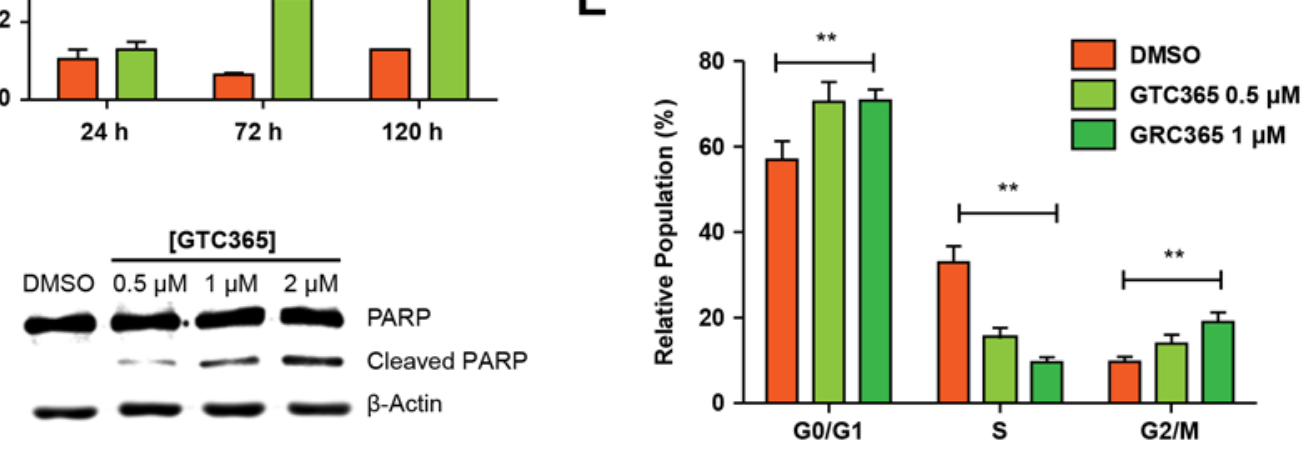

Figure 6. GTC365 induces apoptosis as measured by BAX/BCL2 ratios, Annexin V binding, activation of caspase-3, and PARP cleavage and causes changes in the cell cycle. (A) Increase of BAX/BCL2 ratios by GTC365 in mRNA levels. MCF7 cells were treated with GTC365 for $72 \mathrm{~h}$ and then subjected to qPCR and immunoblot analysis. Relative ratio of BAX/BCL2 was determined compared with DMSO-treated sample. (B) Dose- (upper) and time- (lower) dependent increase of Annexin V binding by GTC365. For dose-dependent response, MCF7 cells were treated with GTC365 for $24 \mathrm{~h}$ and post $-48 \mathrm{~h}$ before Annexin $\mathrm{V}$ binding assay using FACS. For time-dependent response, the cells were treated with compound for 24, 72, and 120 h. (C) Activation of caspase-3/7 (DEVDase) by GTC365. MCF7 cells were treated with GTC365 for $48 \mathrm{~h}$ and staurosporine for $4 \mathrm{hr}$. The supernatant of cell lysate was subjected to the caspase$3 / 7$ assay using DEVD-AFC as a substrate. The fluorescence intensity at $505 \mathrm{~nm}$ was measured, corrected with a concentration of whole protein, and then normalized to a DMSO-treated sample. (D) Immunoblot analysis for detection of PARP cleavage after GTC365 treatment. MCF7 cells were treated with GTC365 for $72 \mathrm{~h}$ before immunoblot analysis. (E) Relative change in populations for G0/G1, S, and G2/M phase following treatment with 0.5 and $1 \mu \mathrm{M}$ GTC365. Cell cycle was analyzed by PI staining. MCF7 cells were treated with GTC365 for $48 \mathrm{~h}$ before FACS analysis. $\mathrm{P}$ values $\left({ }^{*} \mathrm{P}<0.1,{ }^{*} \mathrm{P}<0.01\right.$, and 
$* * * * \mathrm{P}<0.0001)$ were obtained by one-way ANOVA analysis for (A), (B, top), (C), and (E) and by twotailed t-test for (B, bottom). 
connecting two adjacent cells, were observed in GTC365-treated cells after 5 days (Figure S9).

Eventually, most of the cells underwent cell death after exposure to a low dose of GTC365 in 6-9 days

(Figure S10). In summary, knockdown of hTERT by GTC365 resulted in cell death through apoptosis or senescence mediated by telomere shortening and cell cycle arrest.

\section{GTC365 displays potent anticancer activity in hTERT-dependent melanoma cell lines.}

Given that somatic mutation of the hTERT promoter has been shown to enhance promoter activity in the majority of melanomas, ${ }^{45,46}$ we next sought to evaluate the effects of GTC365 on G-quadruplex-regulated hTERT transcription and cell viability in melanoma cell lines as a model of hTERT-dependent cancers with known genetic alterations driving hTERT overexpression. We first identified five melanoma cell lines containing a spectrum of hTERT promoter mutations, UACC-2512 (WT), UACC-903 (G124A), UACC-2528 (G124/125A), UACC-383 (G138/139A), and UACC-1729 (G146A), through Sanger sequencing. We then confirmed the increased hTERT mRNA level in these cells in comparison to the WT promoter cells (Figure 7A). In each of the mutant cells the hTERT mRNA level was increased 6.6-34fold relative to the WT cells. We also determined the mutational status of key oncogenic driver genes in these cell lines, including BRAF, NRAS, KRAS, CDKN2A, and TP53. Notably, these cells were uniform at most key cancer gene loci (BRAF V600E, NRAS WT, KRAS WT, CDKN2A homozygous deletion, and TP53 WT), although the G138/139A cell line was BRAF WT with an NRAS Q61R mutation.

In order to assess the inhibition of cell growth by GTC365, these melanoma cell lines were treated with a range of concentrations of GTC365 for $72 \mathrm{~h}$ (Figure 7B). These cell lines showed a similar dosedependent proportional decrease $(25 \%$ at $1 \mu \mathrm{M})$ in the mRNA level of hTERT in the WT and all mutant cells, although the absolute level of reduction was significantly higher in mutant cells (e.g., G138/139A) that showed higher levels of hTERT expression. GTC365 also decreased the mRNA level of BCL2 in WT and mutant (G146A) melanoma cell lines in a dose-dependent manner (Figure 7C). Next, to assess the selectivity of GTC365 for hTERT-dependent cancer cells relative to normal precursor cells, we compared the effect of a range of GTC265 concentrations on viability at $72 \mathrm{~h}$ in normal human melanocytes (NHM- 
A

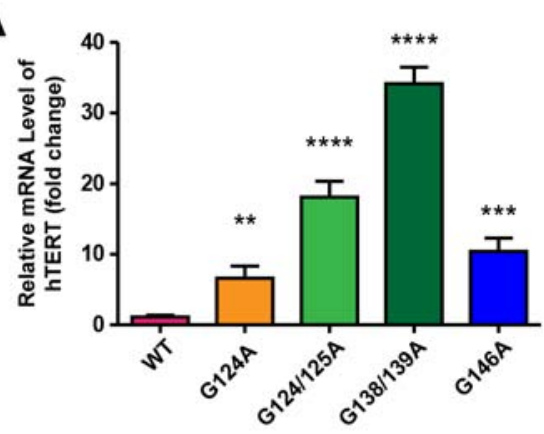

C

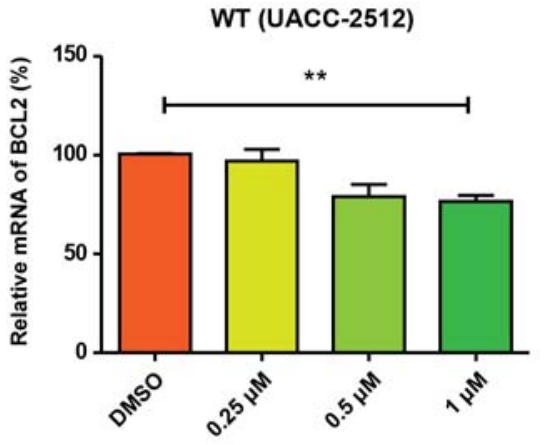

D

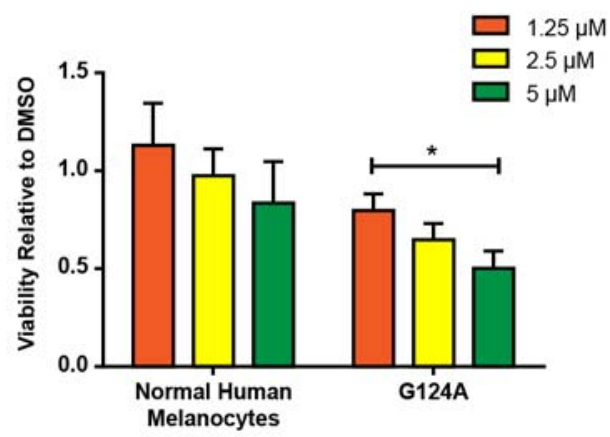

$\mathbf{E}$

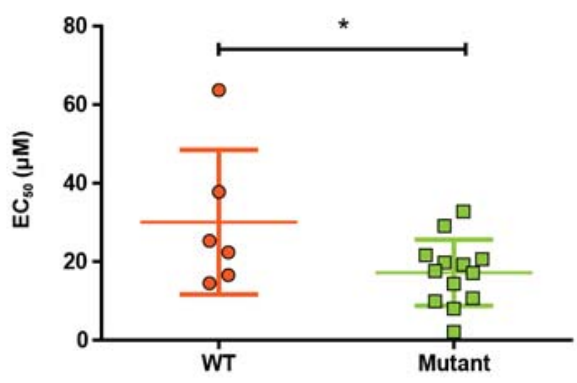

B
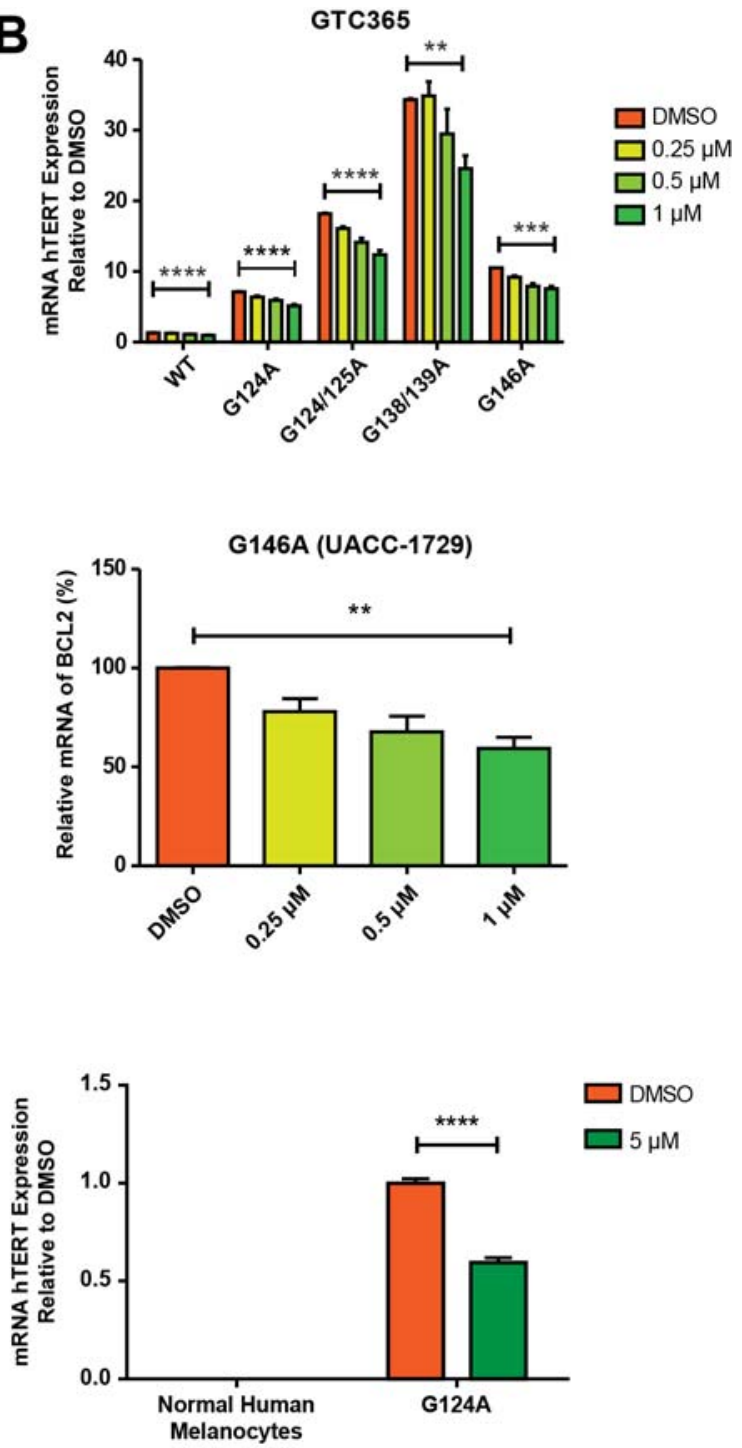

Figure 7. Effect of GTC365 in WT and mutant melanoma cell lines expressing different levels of hTERT. (A) Over-activated transcription of hTERT in melanoma cells with hTERT core promoter mutations compared to the WT cells. (B) Dose-dependent effect of GTC365 on hTERT mRNA level in melanoma cells carrying the G124A, G124/125A, G138/139A, and G146A mutations compared to WT. Cells were treated for $72 \mathrm{~h}$, and then reverse transcription and qPCR were conducted to obtain the relative mRNA of hTERT to GAPDH. (C) Downregulation of BCL2 mRNA level by GTC365 in melanoma cells carrying the hTERT core promoter WT (UACC-2512) and G146A mutant (UACC-1729). Melanoma cells were 
treated with GTC365 for $72 \mathrm{~h}$. (D) Selective reduction in viability (left) and hTERT expression (right) in melanoma cells carrying hTERT core promotor mutations. NHM-002 (normal human melanocytes) and a G124A mutant cell line were treated with vehicle, 1.25, 2.5, and $5 \mu \mathrm{M}$ GTC365 for $72 \mathrm{~h}$. Viability was reduced in hTERT mutant melanoma cells by 50\% (left). GTC365 caused minimal reduction in NHM002 viability and was not statistically significant. hTERT mRNA expression was also reduced in melanoma cells treated with GTC365 for $72 \mathrm{~h}$. hTERT expression was undetectable in NHM-002 cells (right). (E) Differential response to GTC365 in WT and promoter mutant cell lines. Cell lines were treated with GTC365 for $72 \mathrm{~h}$. Mutant cell lines show significantly increased sensitivity to GTC365 compared to WT cell lines. $\mathrm{P}$ values $(* \mathrm{P}<0.05, * * \mathrm{P}<0.01, * * * \mathrm{P}<0.001, * * * * \mathrm{P}<0.0001)$ were obtained by two-tailed ttest for (A), (D) hTERT expression, and (E), and one-way ANOVA analysis for (B), (C), and (D) viability. 
002) relative to UACC-903, a G124A mutant (Figure 7D). Viability was significantly reduced in a dosedependent manner in melanoma cells, dropping below $50 \%$ at $5 \mu \mathrm{M}$. However, only a minimal viability change was seen in normal melanocytes and was not statistically significant. To confirm that the reduction in cell viability was a result of hTERT downregulation, reverse transcription and qPCR were performed to measure the mRNA level of hTERT expression in cells treated with DMSO or $5 \mu \mathrm{M}$ GTC365. hTERT expression was reduced by $41 \%$ in the melanoma cell line after $72 \mathrm{~h}$ but was undetectable in normal melanocytes, even in the absence of GTC365. Finally, in order to broadly assess the selectivity of GTC365 for hTERT promoter mutant versus WT cells, we conducted a 6-point $72 \mathrm{~h}$ MTS proliferation assay to determine $\mathrm{EC}_{50} \mathrm{~S}$ in 14 additional melanoma cell lines with characterized TERT promoter status (19 cell lines total) (Table S2 and Figure 7E). GTC365 showed EC 50 values ranging from $2.11 \mu \mathrm{M}$ (a G124A line) to $63.71 \mu \mathrm{M}$ (a WT line). We also tested BRACO-19 in 4 of these lines and saw similar responses (Table S2). Ultimately, this broad screen shows a significant differential response to GTC365 between WT and mutant melanoma cell lines (Figure 7E) and confirms increased GTC365 activity in mutant cells that express higher levels of hTERT (Figure 7B). These data support that GTC365 reduces cell proliferation through downregulation of hTERT expression via stabilization of the G-quadruplex promoter structure. This mechanism is selective for hTERT-dependent melanomas such as those bearing hTERT promoter mutations.

\section{DISCUSSION}

Limitless proliferation potential due to telomerase activation is one of the original hallmarks of cancer. ${ }^{1}$ hTERT is the key telomerase holoenzyme subunit that confers telomerase activity. ${ }^{89,90}$ Recently it has been shown that specific somatic mutations in the hTERT core promoter element result in a 2-4-fold increase in luciferase activity and that these mutations are commonly found in a number of cancers, most notably in bladder cancer, melanomas, and gliomas, where they are often associated with poor

prognosis. ${ }^{45-47}$ It appears that the level of telomerase activity is the best indicator of patient prognosis. ${ }^{91}$ In 
an attempt to rationalize the molecular basis for the transcriptional effects of these somatic mutations of hTERT, it was first proposed that new ETS transcription factor binding sites are generated in the duplex form of the promoter. ${ }^{45}$ More recently it has been proposed that GABP transcription factors can be recruited to mutant promoter elements in glioblastoma multiforme, ${ }^{52}$ thus providing an additional mechanism for the effects of these mutations. However, these mechanisms cannot fully account for the differences in transcriptional regulation of hTERT conferred by mutant promoters. Our work has previously shown the importance of hTERT promoter G-quadruplexes in the regulation of hTERT transcription. We have previously demonstrated that the core hTERT promoter sequence forms a tandem set of G-quadruplexes and have proposed that when these structures are stabilized by compounds that bind to them, this is what leads to inhibition of hTERT transcription. ${ }^{41}$ Thus, this mode of hTERT regulation has direct implications for therapy. Notably, catalytic inhibition of telomerase has been the major goal for drugs designed to destabilize telomeres through inhibition of telomere elongation or stimulation of telomere uncapping. However, direct repression of hTERT promoter activity has distinct advantages associated with impairing various functions for cell survival, such as lowering BCL2 and consequently inducing apoptosis ${ }^{14,15,88}$ as well as reducing telomere maintenance by directly lowering hTERT levels.

The first question we addressed was whether the somatic mutations that led to overexpression of hTERT in cancer cells could be attributed to their effect on the cooperative folding process. Since all the somatic mutation sites found in the hTERT promoter are associated with either the hairpin loop (G138/139A and G146A) or the 5-12 G-quadruplex (G124A and G124/125A), which have been both shown to be important in the early folding process, ${ }^{42}$ this seemed like an attractive postulate to explain the effect of these mutations on hTERT activation. Indeed, both the final folded form and the relative populations of intermediates were severely compromised relative to the WT species. Because it seemed likely that the fully folded form would be required for formation of a functional silencer element, then a small molecule pharmacoperone that could recognize and bind to early intermediates in the folding 
pathway might rescue the folding pathway in mutants that were compromised in this critical folding process (Figure 8; compare pathways $\mathrm{C}$ to $\mathrm{D}$ and $\mathrm{C}$ to $\mathrm{E}$ to $\mathrm{B}$ ).
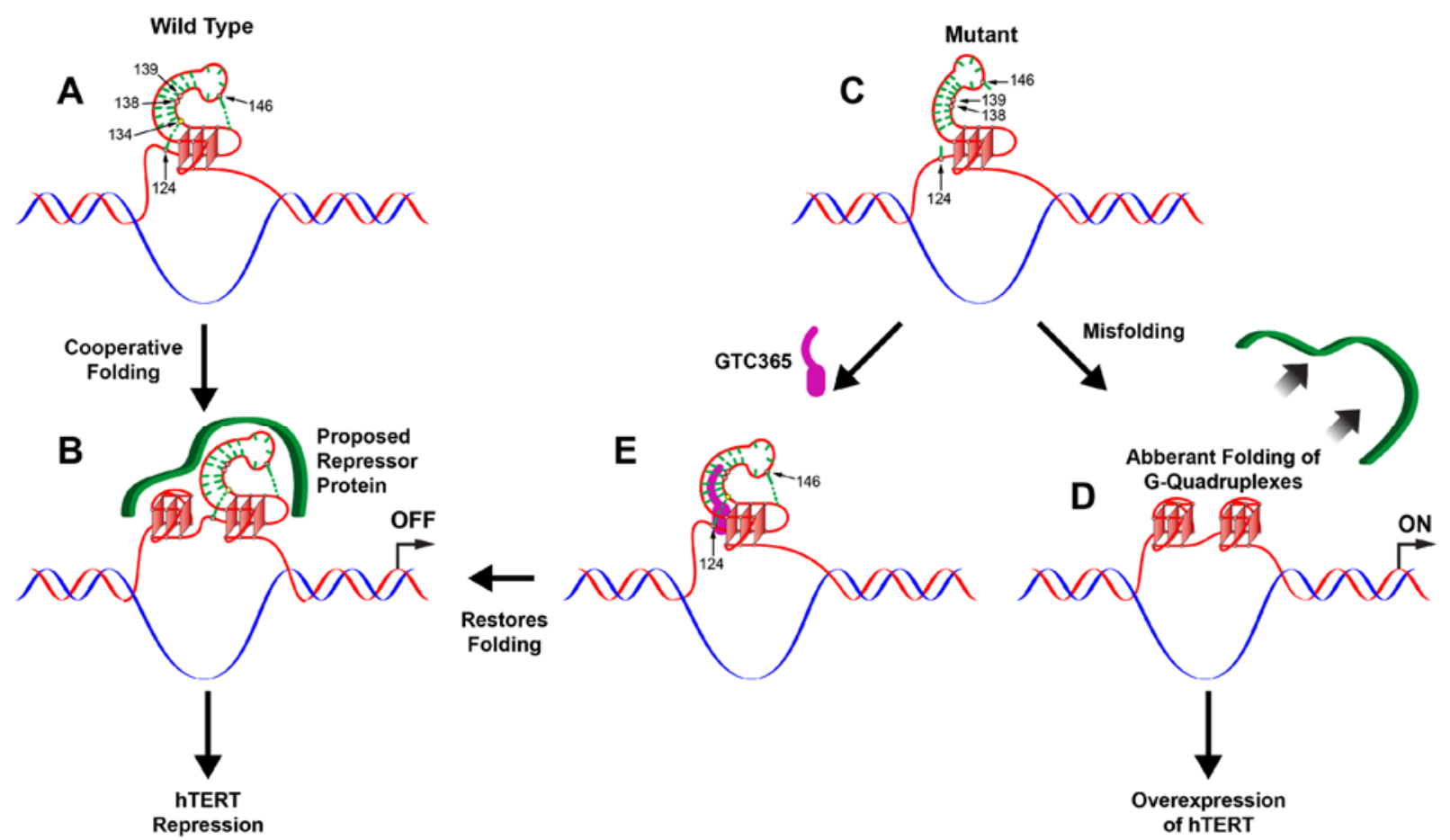

of hTERT

Figure 8. Cartoon illustrating the proposed effect of somatic mutations on the cooperative folding process, resulting in activation of hTERT transcription and how GTC365 is proposed to act as a pharmacoperone to restore the silencer function. For the WT cooperative folding pathway, the loop of the hairpin is in proximity to a loop in the adjacent G-quadruplex to provide critical tertiary interactions, leading to the functional silencer element (A to B). For illustrative purposes, G146 is shown making this interaction and G124 is base-paired to C134 at the bottom of the hairpin loop. In the case of any of the mutant promoter elements, the loss of one of these critical tertiary interactions between the hairpin and the adjacent G-quadruplex, which is required for steering the correct folding pathways then leads to misfolding of the 5-12 G-quadruplex and a nonfunctional silencer element (C to D). The binding of the pharmacoperone GTC365 to the mutant hairpin loop restores the folding pathway, leading to a functional silencer element ( $\mathrm{C}$ to $\mathrm{E}$ to $\mathrm{B})$. The positions of the somatic mutations are shown in the hairpin loop and associated tetrad in $\mathrm{A}$ and $\mathrm{C}$. The green ribbon in $\mathrm{B}$ and $\mathrm{D}$ is a proposed repressor protein that uniquely recognizes the fully folded 5-12 G-quadruplex associated with the silencer element.

We identified, through a FRET screening method, the propylguanidino-acridine derivative GTC365, which binds to the 5-12 G-quadruplex to lower hTERT transcription by directly targeting this promoter element. This compound has different biophysical, biochemical, and biological effects than BRACO-19 (Table 1) that we believe are uniquely associated with the propylguanidino side-chain found exclusively in GTC365. On the basis of results from DMS footprinting, binding of GTC365 to the fully folded form of the 5-12 G-quadruplex positions the guanidinium group in close proximity to the GC base pairs at 
Table 1. Summary of the comparison of the biochemical and biological effects of GTC365 and BRACO-19.

\begin{tabular}{|l|l|}
\hline \multicolumn{1}{|c|}{ Experiments to compare } & \multicolumn{1}{c|}{$\begin{array}{c}\text { Results and conclusions from these comparison experiments } \\
\text { between GTC365 and BRACO19 }\end{array}$} \\
\hline $\begin{array}{l}\text { Effect on luciferase activity } \\
\text { using E-box mutation } \\
\text { (Figure 4A) }\end{array}$ & $\begin{array}{l}\text { GTC365 acts directly at the hTERT promoter level, whereas BRACO- } \\
\text { 19 requires the E-box for lowering of hTERT implying that only } \\
\text { BRACO-19 requires the E-box for suppression of hTERT expression. }\end{array}$ \\
\hline $\begin{array}{l}\text { Effects on MYC and BCL2 } \\
\text { gene expression (Figure 4B) }\end{array}$ & $\begin{array}{l}\text { As anticipated from above, GTC365 has no effect on MYC expression } \\
\text { and works directly through the hTERT promoter to lower BCL2, } \\
\text { whereas BRACO-19 lowers hTERT expression via MYC and has no } \\
\text { effect on BCL2 expression, demonstrating quite different promoter } \\
\text { targets for the two compounds. }\end{array}$ \\
\hline $\begin{array}{l}\text { Effects on telomerase } \\
\text { activity (Figure 5A) }\end{array}$ & $\begin{array}{l}\text { At much lower concentrations of compound, GTC365 has a much more } \\
\text { potent effect on telomerase activity than BRACO-19, suggesting that } \\
\text { the underlying mechanism for these effects are different, which is } \\
\text { consistent with the published results that BRACO-19 targets the } \\
\text { telomeric G-quadruplexes and as demonstrated here GTC365 targets } \\
\text { the hTERT promoter. }\end{array}$ \\
\hline $\begin{array}{l}\text { Effects on telomere length } \\
\text { (Figure 5B) and effects on } \\
\text { senescence (Figure 5C) }\end{array}$ & $\begin{array}{l}\text { As a consequence of the direct targeting of the hTERT promoter, which } \\
\text { produces a more potent effect on telomerase activity than BRACO-19, } \\
\text { the downstream biological effects, telomere shortening, and consequent } \\
\text { senescence are also more rapid (telomere shortening) and more potent } \\
\text { than BRACO-19. }\end{array}$ \\
\hline $\begin{array}{l}\text { Effects of recovery of } \\
\text { population species (Figure } \\
\text { 5D) and effects on velocity } \\
\text { of folding (Figure 5E) }\end{array}$ & $\begin{array}{l}\text { GTC365 has a much more potent effect on the velocity of refolding of } \\
\text { the mutant promoter than BRACO-19 and restores the fully folded form } \\
\text { of the mutant promoter much more effectively than BRACO-19. }\end{array}$ \\
\hline
\end{tabular}

positions $138 / 139$ in the hairpin loop and the acridine moiety in proximity to the $124 / 125$ positions in the associated G-quadruplex (Figure 3F). Thus we propose that GTC365 can act as a chaperone in both accelerating the folding of the WT and steering the cooperative folding of a mutated 5-12 G-quadruplex to a functional transcriptional repressor (Figure 8; $\mathrm{A}$ to $\mathrm{B}$ in the WT and $\mathrm{C}$ to $\mathrm{E}$ to $\mathrm{B}$ in the mutants). We have previously shown that the cooperative refolding of the 5-12 G-quadruplex requires the simultaneous folding of the hairpin and the associated G-quadruplex, ${ }^{42}$ which is due to tertiary interactions between the hairpin and G-quadruplex structure. Since these interactions occur at early intermediates while the energy barriers may be small, the intermolecular interactions between, for example, the guanidinium group and the 15-mer are still able to drive the secondary structural transitions. Significantly, the 15-mer hairpin contains the G138/139A and G146A mutants and the associated G-quadruplex contains the G124/125A mutant. Mutations that lead to loss of these tertiary interactions rationalizes why these somatic mutations 
could lead to lower populations of the fully functional folded species. This is strikingly similar to the intrinsic dynamic behavior of RNA, which is used in riboswitches where metabolite-based effectors such as amino acids and nucleotides possess a similar chaperone activity to direct different folding pathways. ${ }^{92}$ In addition, mutations in the intronic region near the 5 splice site of exon 10 in tau pre-mRNA have been associated with frontotemporal dementia and parkinsonism. ${ }^{93}$ These mutations are found in the putative stem loop that destabilize the structure, altering the tau protein isoforms by alternative splicing. ${ }^{94,95}$ This stem loop in the tau pre-mRNA has a striking similarity to the heteroduplex loop in the hTERT promoter (Figure 9), and since stabilization of the stem loop reverses the splicing pattern associated with neurodegeneration, ${ }^{96}$ it has been proposed that small molecules that stabilize this stem loop would provide new ways to treat dementia. ${ }^{97}$ Indeed, novantrone (mitoxantrone) stabilizes the tau pre-mRNA by binding to the stem loop, and while it provides a rational basis for development of new therapeutics, the lack of specificity is a barrier to further therapeutic development. ${ }^{97}$ Last, this approach to drug therapy is analogous to the use of pharmacoperone molecules to treat misfolding protein problems, such as those in cystic fibrosis. ${ }^{98}$ Among the somatic mutations found in the hTERT promoter element, the single G124A and G146A mutations are exclusively found in glioblastoma multiforme and bladder cancer, whereas the double mutations G138/139A and G124/125A are absent. On the basis of our model, in which we propose that there are key interactions between the hairpin loop and the adjacent G-quadruplex that give rise to a tertiary complex, which is important in steering the folding of the 5-12 G-quadruplex, it seems reasonable to propose that the G124A and G146A mutants are special cases and that either mutation would result in loss of different key interactions. Both mutants are located at potentially critical positions in the 5-12 Gquadruplex. G124 is directly adjacent to the G-quadruplex, and G146 is in the hairpin loop that is involved in the tertiary interaction. G124 is therefore in proximity for base pairing to C134 at the junction of the hairpin loop, which we propose may play a key role in positioning the hairpin and G-quadruplex for cooperative folding. We have already shown that the tertiary interaction between the hairpin loop and the G-quadruplex results in a folded structure that is stable by $6 \mathrm{kcal} / \mathrm{mol}$ energy. ${ }^{42}$ Thus, G146 may play a key role in positioning the hairpin loop closer to a loop in the associated G-quadruplex and facilitate this 


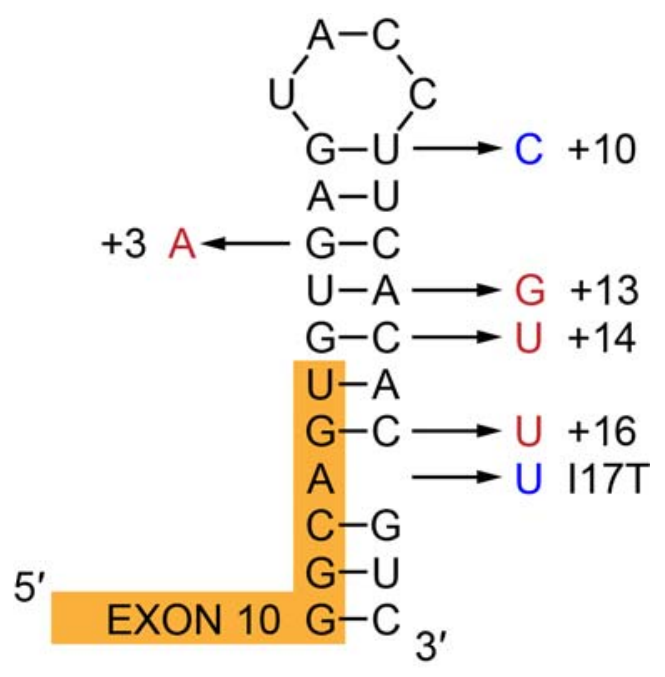

Figure 9. Sequence and secondary structure of mutant human tau exon 10 splicing regulatory element. Destabilizing mutations at the $+3,+13,+14$, and +16 positions (in red) are linked to familial neurodegenerative diseases and increase inclusion of exon $10 .^{93,99-101}$ In contrast, stabilizing mutations at +10 and the I17T insertion (in blue) decrease inclusion of exon 10 in vitro. ${ }^{96}$ Reprinted from Chemistry \& Biology, vol. 16, 2009, Zheng et al., Structural basis for stabilization of the tau pre-mRNA splicing regulatory element by novatrone [sic] (mitoxantrone), 557-566, with permission from Elsevier. 
tertiary interaction. Therefore, loss of either interaction results in the formation of a misfolded final structure, which is energetically less stable. In support of this postulate, the increase in the initial rate of folding produced by GTC365 for these two mutants is much faster than for the G138/139A mutant. GTC365 potentially permits the mutants to recover this tertiary stabilization energy lost due to the G124A or G146A mutation. For the G138/139A mutant the initial rate of folding is not perceptibly changed by GTC365, although the population of the more fully folded form is significantly increased, as shown by the single molecule experiments. We propose that the role of the guanidino group in GTC365 in this case is one in which the drug plays a more restabilization role than reorienting the tertiary complex due to loss of two key base-pair interactions. Similar to the G138/139A, the G124/125A double mutant is more destabilizing than either of the single mutations. However, since this double mutant contains the G124A mutation, GTC365 still plays an important role in recovering the tertiary interaction and the initial rate of folding is accelerated.

The unique chaperone effect of the propylguanidino side-chain present in GTC365 in steering the folding of the functionally active transcriptional repressor can explain the quite different biochemical and biological effects of this compound versus BRACO-19 (Table 1). GTC365 directly represses hTERT expression and potently lowers telomerase activity, while BRACO-19 only indirectly lowers hTERT, most likely by lowering of MYC gene expression. The downregulation of hTERT transcription by GTC365 produces various anti-functions of hTERT, thereby reducing cancer cell survival. These shortterm effects of GTC365 are induction of apoptosis, reduction in viability, and decrease of telomerase activity and telomere length with associated senescence and changes in cell cycle. Reassuringly, these biological effects observed with GTC365 are largely in accord with previous studies using siRNA targeted to hTERT. For example, Shammas and coworkers showed that treatment with hTERT siRNA induced senescence and apoptosis and decreased telomerase activity and telomere length. ${ }^{102}$ As anticipated, the biological effects of GTC365 are quite different to the cellular response to DNA damageinducing G-quadruplex binders, such as BRACO-19 derivatives, ${ }^{103}$ RHPS4, ${ }^{104}$ TMPyP4,${ }^{105}$ and 307A,,${ }^{106}$ that induce accumulation in the cell cycle in both $\mathrm{S}$ and G2/M phases. The G2/M phase arrest observed 
with GTC365 is consistent with known effects of hTERT modulating mitosis. For example, it has been suggested that hTERT is involved in G2/M mitotic spindle function and checkpoint in mitosis because hTERT dissociates from chromosomes in mitotic prophase. ${ }^{107}$

The unique mechanism of action of GTC365, which involves kinetics effects mediated by facilitating the cooperative folding of the G-quadruplex silencer element, is in contrast to other Gquadruplex-interactive compounds like BRACO-19 that produce stabilization of G-quadruplexes in, for example, telomeric sequences and promoter elements, resulting in inhibition of telomere elongation and gene expression. Because the cooperative folding is initiated in the heteroduplex loop, the molecular target of GTC365 is not the G-quadruplex, which provides a quite different drug-targeting approach that might be more selective than existing strategies; but this, of course, depends on the presence of such a molecular mechanism in facilitating the formation of the active silencer element.

Finally, we examined the selective cytotoxic effects of GTC365 on a model cancer with a known genetic etiology that drives hTERT upregulation. We used melanoma cell lines that overexpress hTERT as a consequence of mutations in the 5-12 G-quadruplex. We compared hTERT expression, BCL2 expression, and viability in normal melanocytes as well as up to 19 cell lines with variable hTERT promoter status (WT, G124A, G124/125A, G138/139A, and G146A). Notably, we found that GTC365 was minimally cytotoxic in normal melanocytes but exhibited significant dose-dependent cell killing in melanoma cells. We also found that, although a range of hTERT expression and responses to GTC365 was seen in melanoma cell lines, GTC365's cytotoxicity was significantly more pronounced in hTERT promoter mutants than in WT melanoma cells. Although hTERT promoter mutations occur in the majority of melanomas, other mechanisms may also contribute to hTERT activation, including copy number changes, translocations, missense mutations, and epigenetic changes. Therefore, it is not wholly surprising that there is a wide distribution of responses to GTC365 in promoter WT cell lines. Overall, these studies clearly show the therapeutic opportunities for targeting cancer cells that overexpress hTERT, irrespective of the underlying mechanism. 
In summary, we have characterized the disruptive effect of somatic mutations on the pathway leading to cooperative folding of the 5-12 G-quadruplex, in which formation of the functional active repressor is required for effective silencing of the hTERT promoter element. The propylguanidinoacridine compound GTC365 was identified as a compound able to reverse the transcription-activating effect of these mutations by acting as a pharmacoperone molecule that steers the cooperative folding to partially restore the silencing ability of the mutant G-quadruplexes. In contrast to approaches that target either the telomeric structure or siRNA modulating post-transcriptional events, the direct targeting of the hTERT promoter element produces biological effects, such as apoptosis, telomere shortening, cell cycle arrest, and failure of cell division, leading to nonapoptotic cell death, that can be observed within 2-5 days, which makes this an attractive therapeutic strategy for treating cancer patients with hTERT dependency, whether due to promoter mutation or other genetic aberrations. 


\section{Supporting Information}

Supporting Information contains 10 figures and 3 tables.

\section{Author Information}

*E-mail: hurley@pharmacy.arizona.edu. Phone: 520-626-5621. Fax: 520-626-0034.

\section{Notes}

Laurence Hurley and Vijay Gokhale have a financial interest in Tetragene, a G-quadruplex-targeting company.

\section{Acknowledgments}

We are grateful to Dr. David Bishop for preparing, proofreading, and editing the final version of the manuscript and figures. This research was supported by the National Science Foundation (CHE-1026532 and CHE-1415883 for HM) and the National Institutes of Health (5R01CA153821 and 1R01GM085585 for LHH). W.P.D.H, J.E.S., A.S., and J.M.T. received research support from a Stand Up To CancerMelanoma Research Alliance/Melanoma Dream Team Translational Cancer Research Grant (SU2CAACR-DT0612). Stand Up To Cancer is a program of the Entertainment Industry Foundation administered by the American Association for Cancer Research (AACR).

\section{REFERENCES}

(1) Hanahan, D.; Weinberg, R. A. Cell 2011, 144, 646.

(2) Agrawal, A.; Dang, S.; Gabrani, R. Recent Pat. Anticancer Drug Discov. 2012, 7, 102.

(3) Djojosubroto, M. W.; Chin, A. C.; Go, N.; Schaetzlein, S.; Manns, M. P.; Gryaznov, S.; Harley, C. B.; Rudolph, K. L. Hepatology 2005, 42, 1127. 
(4) Goldblatt, E. M.; Gentry, E. R.; Fox, M. J.; Gryaznov, S. M.; Shen, C.; Herbert, B.-S. Mol. Cancer Ther. 2009, 8, 2027.

(5) Hashizume, R.; Ozawa, T.; Gryaznov, S. M.; Bollen, A. W.; Lamborn, K. R.; Frey, W. H.; Deen, D. F. Neuro Oncol. 2008, 10, 112.

(6) Hochreiter, A. E.; Xiao, H.; Goldblatt, E. M.; Gryaznov, S. M.; Miller, K. D.; Badve, S.; Sledge, G. W.; Herbert, B.-S. Clin. Cancer Res. 2006, 12, 3184.

(7) Joseph, I.; Tressler, R.; Bassett, E.; Harley, C.; Buseman, C. M.; Pattamatta, P.; Wright, W. E.; Shay, J. W.; Go, N. F. Cancer Res. 2010, 70, 9494.

(8) Marian, C. O.; Cho, S. K.; Mcellin, B. M.; Maher, E. A.; Hatanpaa, K. J.; Madden, C. J.; Mickey, B. E.; Wright, W. E.; Shay, J. W.; Bachoo, R. M. Clin. Cancer Res. 2010, 16, 154.

(9) Chiappori, A.; Kolevska, T.; Spigel, D.; Hager, S.; Rarick, M.; Gadgeel, S.; Blais, N.; Von Pawel, J.; Hart, L.; Reck, M. Ann. Oncol. 2015, 26, 354.

(10) Kozloff, M.; Sledge, G.; Benedetti, F.; Starr, A.; Wallace, J.; Stuart, M.; Gruver, D.; Miller, K. J. Clin. Oncol. 2010, 28, 15s.

(11) Salloum, R.; Hummel, T.; Kumar, S.-S.; Dorris, K.; Li, S.; Lin, T.; Onar-Thomas, A.; Miles, L.; Toung-Poussaint, T.; Stevenson, C. Neuro Oncol. 2015, 17, iii39.

(12) Baerlocher, G. M.; Oppliger Leibundgut, E.; Ottmann, O. G.; Spitzer, G.; Odenike, O.; McDevitt, M. A.; Röth, A.; Daskalakis, M.; Burington, B.; Stuart, M.; Snyder, D. S. N. Engl. J. Med. 2015, 373,920 .

(13) Tefferi, A.; Lasho, T. L.; Begna, K. H.; Patnaik, M. M.; Zblewski, D. L.; Finke, C. M.; Laborde, R. R.; Wassie, E.; Schimek, L.; Hanson, C. A. N. Engl. J. Med. 2015, 373, 908.

(14) Masutomi, K.; Possemato, R.; Wong, J. M.; Currier, J. L.; Tothova, Z.; Manola, J. B.; Ganesan, S.; Lansdorp, P. M.; Collins, K.; Hahn, W. C. Proc. Natl. Acad. Sci. USA 2005, 102, 8222.

(15) Del Bufalo, D.; Rizzo, A.; Trisciuoglio, D.; Cardinali, G.; Torrisi, M. R.; Zangemeister-Wittke, U.; Zupi, G.; Biroccio, A. Cell Death Differ. 2005, 12, 1429.

(16) Mukherjee, S.; Firpo, E. J.; Wang, Y.; Roberts, J. M. Proc. Natl. Acad. Sci. USA 2011, 108, E1363. 
(17) Hiyama, E.; Tatsumoto, N.; Kodama, T.; Hiyama, K.; Shay, J.; Yokoyama, T. Int. J. Oncol. 1996, 9, 453.

(18) Kim, N. W.; Piatyszek, M. A.; Prowse, K. R.; Harley, C. B.; West, M. D.; Ho, P. d. L.; Coviello, G. M.; Wright, W. E.; Weinrich, S. L.; Shay, J. W. Science 1994, 266, 2011.

(19) Yui, J.; Chiu, C.-P.; Lansdorp, P. M. Blood 1998, 91, 3255.

(20) Cao, Y.; Bryan, T. M.; Reddel, R. R. Cancer Sci. 2008, 99, 1092.

(21) Zhang, A.; Zheng, C.; Lindvall, C.; Hou, M.; Ekedahl, J.; Lewensohn, R.; Yan, Z.; Yang, X.; Henriksson, M.; Blennow, E.; Nordenskjöld, M.; Zetterberg, A.; Björkholm, M.; Gruber, A.; Xu, D. Cancer Res. 2000, 60, 6230.

(22) Ducrest, A. L.; Amacker, M.; Mathieu, Y. D.; Cuthbert, A. P.; Trott, D. A.; Newbold, R. F.; Nabholz, M.; Lingner, J. Cancer Res. 2001, 61, 7594.

(23) Günes, C.; Lichtsteiner, S.; Vasserot, A. P.; Englert, C. Cancer Res. 2000, 60, 2116.

(24) Takakura, M.; Kyo, S.; Kanaya, T.; Hirano, H.; Takeda, J.; Yutsudo, M.; Inoue, M. Cancer Res. 1999, 59, 551 .

(25) Guilleret, I.; Yan, P.; Grange, F.; Braunschweig, R.; Bosman, F. T.; Benhattar, J. Int. J. Cancer 2002, 101, 335 .

(26) Kyo, S.; Takakura, M.; Fujiwara, T.; Inoue, M. Cancer Sci. 2008, 99, 1528.

(27) Akıncılar, S. C.; Low, K. C.; Liu, C. Y.; Yan, T. D.; Oji, A.; Ikawa, M.; Li, S.; Tergaonkar, V. FEBS Lett. 2015, 589, 974.

(28) Yi, X.; Shay, J. W.; Wright, W. E. Nucleic Acids Res. 2001, 29, 4818.

(29) Castelo-Branco, P.; Choufani, S.; Mack, S.; Gallagher, D.; Zhang, C.; Lipman, T.; Zhukova, N.; Walker, E. J.; Martin, D.; Merino, D. Lancet Oncol. 2013, 14, 534.

(30) Shay, J.; Bacchetti, S. Eur. J. Cancer 1997, 33, 787.

(31) Murofushi, Y.; Nagano, S.; Kamizono, J.; Takahashi, T.; Fujiwara, H.; Komiya, S.; Matsuishi, T.; Kosai, K. Int. J. Oncol. 2006, 29, 681.

(32) Wang, S.; Zhao, Y.; Hu, C.; Zhu, J. Nucleic Acids Res. 2009, 37, 2618. 
(33) Gu, J.; Kagawa, S.; Takakura, M.; Kyo, S.; Inoue, M.; Roth, J. A.; Fang, B. Cancer Res. 2000, 60, 5359.

(34) Balasubramanian, S.; Hurley, L. H.; Neidle, S. Nat. Rev. Drug Discov. 2011, 10, 261.

(35) Gonzalez, V.; Guo, K.; Hurley, L.; Sun, D. J. Biol. Chem. 2009, 284, 23622.

(36) Brown, R. V.; Danford, F. L.; Gokhale, V.; Hurley, L. H.; Brooks, T. A. J. Biol. Chem. 2011, 286, 41018.

(37) Felsenstein, K. M.; Saunders, L. B.; Simmons, J. K.; Leon, E.; Calabrese, D. R.; Zhang, S.;

Michalowski, A.; Gareiss, P.; Mock, B. A.; Schneekloth, J. S., Jr. ACS Chem. Biol. 2016, 11, 139.

(38) Neidle, S. J. Med. Chem. 2016, 59, 5987.

(39) Kang, H. J.; Kendrick, S.; Hecht, S. M.; Hurley, L. H. J. Am. Chem. Soc. 2014, 136, 4172.

(40) Kendrick, S.; Kang, H. J.; Alam, M. P.; Madathil, M. M.; Agrawal, P.; Gokhale, V.; Yang, D.;

Hecht, S. M.; Hurley, L. H. J. Am. Chem. Soc. 2014, 136, 4161.

(41) Palumbo, S. L.; Ebbinghaus, S. W.; Hurley, L. H. J. Am. Chem. Soc. 2009, 131, 10878.

(42) Yu, Z.; Gaerig, V.; Cui, Y.; Kang, H.; Gokhale, V.; Zhao, Y.; Hurley, L. H.; Mao, H. J. Am. Chem. Soc. 2012, 134, 5157.

(43) Chaires, J. B.; Trent, J. O.; Gray, R. D.; Dean, W. L.; Buscaglia, R.; Thomas, S. D.; Miller, D. M. PLoS One 2014, 9, e115580.

(44) Horikawa, I.; Chiang, Y. J.; Patterson, T.; Feigenbaum, L.; Leem, S. H.; Michishita, E.; Larionov, V.; Hodes, R. J.; Barrett, J. C. Proc. Natl. Acad. Sci. USA 2005, 102, 18437.

(45) Horn, S.; Figl, A.; Rachakonda, P. S.; Fischer, C.; Sucker, A.; Gast, A.; Kadel, S.; Moll, I.; Nagore, E.; Hemminki, K.; Schadendorf, D.; Kumar, R. Science 2013, 339, 959.

(46) Huang, F. W.; Hodis, E.; Xu, M. J.; Kryukov, G. V.; Chin, L.; Garraway, L. A. Science 2013, 339, 957.

(47) Killela, P. J.; Reitman, Z. J.; Jiao, Y.; Bettegowda, C.; Agrawal, N.; Diaz, L. A.; Friedman, A. H.; Friedman, H.; Gallia, G. L.; Giovanella, B. C.; Grollman, A. P.; He, T. C.; He, Y.; Hruban, R. H.; Jallo, G. I.; Mandahl, N.; Meeker, A. K.; Mertens, F.; Netto, G. J.; Rasheed, B. A.; Riggins, G. J.; 
Rosenquist, T. A.; Schiffman, M.; Shih, I. M.; Theodorescu, D.; Torbenson, M. S.; Velculescu, V. E.; Wang, T. L.; Wentzensen, N.; Wood, L. D.; Zhang, M.; McLendon, R. E.; Bigner, D. D.; Kinzler, K. W.; Vogelstein, B.; Papadopoulos, N.; Yan, H. Proc. Natl. Acad. Sci. USA 2013, 110, 6021.

(48) Vinagre, J.; Almeida, A.; Pópulo, H.; Batista, R.; Lyra, J.; Pinto, V.; Coelho, R.; Celestino, R.; Prazeres, H.; Lima, L.; Melo, M.; da Rocha, A. G.; Preto, A.; Castro, P.; Castro, L.; Pardal, F.; Lopes, J. M.; Santos, L. L.; Reis, R. M.; Cameselle-Teijeiro, J.; Sobrinho-Simões, M.; Lima, J.; Máximo, V.; Soares, P. Nature Comm. 2013, 4, 2185.

(49) Kinde, I.; Munari, E.; Faraj, S. F.; Hruban, R. H.; Schoenberg, M.; Bivalacqua, T.; Allaf, M.; Springer, S.; Wang, Y.; Diaz, L. A. Cancer Res. 2013, 73, 7162.

(50) Quaas, A.; Oldopp, T.; Tharun, L.; Klingenfeld, C.; Krech, T.; Sauter, G.; Grob, T. J. Virchows Arch. 2014, 465, 673.

(51) Bell, R. J. A.; Rube, H. T.; Xavier-Magalhães, A.; Costa, B. M.; Mancini, A.; Song, J. S.; Costello, J. F. Mol. Cancer Res. 2016, 14, 315.

(52) Bell, R. J.; Rube, H. T.; Kreig, A.; Mancini, A.; Fouse, S. D.; Nagarajan, R. P.; Choi, S.; Hong, C.; He, D.; Pekmezci, M.; Wiencke, J. K.; Wrensch, M. R.; Chang, S. M.; Walsh, K. M.; Myong, S.; Song, J. S.; Costello, J. F. Science 2015, 348, 1036.

(53) Flory, E.; Hoffmeyer, A.; Smola, U.; Rapp, U. R.; Bruder, J. T. J. Virol. 1996, 70, 2260.

(54) Dhakal, S.; Schonhoft, J. D.; Koirala, D.; Yu, Z.; Basu, S.; Mao, H. J. Am. Chem. Soc. 2010, 132, 8991.

(55) Mao, H.; Luchette, P. Sensors and Actuators B: Chemical 2008, 129, 764.

(56) Baumann, C. G.; Smith, S. B.; Bloomfield, V. A.; Bustamante, C. Proc. Natl. Acad. Sci. USA 1997, 94,6185 .

(57) Dhakal, S.; Cui, Y.; Koirala, D.; Ghimire, C.; Kushwaha, S.; Yu, Z.; Yangyuoru, P. M.; Mao, H. Nucleic Acids Res. 2013, 41, 3915.

(58) Yu, Z.; Mao, H. Chem. Rec. 2013, 13, 102. 
(59) Greenleaf, W. J.; Frieda, K. L.; Foster, D. A.; Woodside, M. T.; Block, S. M. Science 2008, 319, 630.

(60) Laurence, T. A.; Kong, X.; Jager, M.; Weiss, S. Proc. Natl. Acad. Sci. USA 2005, 102, 17348.

(61) Membrino, A.; Cogoi, S.; Pedersen, E. B.; Xodo, L. E. PLoS One 2011, 6, e24421.

(62) Pavey, S.; Johansson, P.; Packer, L.; Taylor, J.; Stark, M.; Pollock, P. M.; Walker, G. J.; Boyle, G. M.; Harper, U.; Cozzi, S.-J. Oncogene 2004, 23, 4060.

(63) Byron, S. A.; Gartside, M. G.; Wellens, C. L.; Mallon, M. A.; Keenan, J. B.; Powell, M. A.; Goodfellow, P. J.; Pollock, P. M. Cancer Res. 2008, 68, 6902.

(64) Castellano, M.; Pollock, P. M.; Walters, M. K.; Sparrow, L. E.; Down, L. M.; Gabrielli, B. G.; Parsons, P. G.; Hayward, N. K. Cancer Res. 1997, 57, 4868.

(65) Qin, J.-Z.; Stennett, L.; Bacon, P.; Bodner, B.; Hendrix, M. J.; Seftor, R. E.; Seftor, E. A.; Margaryan, N. V.; Pollock, P. M.; Curtis, A. Mol. Cancer Ther. 2004, 3, 895.

(66) Venteicher, A. S.; Meng, Z.; Mason, P. J.; Veenstra, T. D.; Artandi, S. E. Cell 2008, 132, 945.

(67) Reed, J.; Gunaratnam, M.; Beltran, M.; Reszka, A. P.; Vilar, R.; Neidle, S. Anal. Biochem. 2008, $380,99$.

(68) Cawthon, R. M. Nucleic Acids Res. 2002, 30, e47.

(69) Debacq-Chainiaux, F.; Erusalimsky, J. D.; Campisi, J.; Toussaint, O. Nat. Protoc. 2009, 4, 1798.

(70) Cui, Y.; Koirala, D.; Kang, H.; Dhakal, S.; Yangyuoru, P.; Hurley, L. H.; Mao, H. Nucleic Acids Res. 2014, 42, 5755.

(71) Giancola, C.; Pagano, B. Top. Curr. Chem. 2013, 330, 211.

(72) Finlay, G. J.; Atwell, G. J.; Baguley, B. C. Oncol. Res. 1999, 11, 249.

(73) Burger, A. M.; Dai, F.; Schultes, C. M.; Reszka, A. P.; Moore, M. J.; Double, J. A.; Neidle, S. Cancer Res. 2005, 65, 1489.

(74) Xiong, Y.; Sundaralingam, M. Protein-nucleic acid interaction: major groove recognition determinants. eLS [Online Early Access]. DOI: doi: 10.1038/npg.els.0003138. Published Online: 2001. http://www.els.net 
(75) Zhao, Y.; Cheng, D.; Wang, S.; Zhu, J. Nucleic Acids Res. 2014, 42, 10385.

(76) Siddiqui-Jain, A.; Grand, C. L.; Bearss, D. J.; Hurley, L. H. Proc. Natl. Acad. Sci. USA 2002, 99 , 11593.

(77) Mazzucchelli, G. D.; Gabelica, V.; Smargiasso, N.; Fléron, M.; Ashimwe, W.; Rosu, F.; De PauwGillet, M.-C.; Riou, J.-F.; De Pauw, E. Proteome Sci. 2008, 6, 12.

(78) Varshney, A.; Ramakrishnan, S. K.; Sharma, A.; Santosh, B.; Bala, J.; Yadava, P. K.; Jaiswal, R. K. Gene 2014, 547, 211.

(79) Wang, T.; Xue, Y.; Wang, M.; Sun, Q. Oncol. Rep. 2012, 28, 1153.

(80) Zhong, Y. Q.; Xia, Z. S.; Fu, Y. R.; Zhu, Z. H. J. Dig. Dis. 2010, 11, 176.

(81) Bièche, I.; Noguès, C.; Paradis, V.; Olivi, M.; Bedossa, P.; Lidereau, R.; Vidaud, M. Clin. Cancer Res. 2000, 6, 452.

(82) Allsopp, R. C.; Harley, C. B. Exp. Cell Res. 1995, 219, 130.

(83) Gunaratnam, M.; Greciano, O.; Martins, C.; Reszka, A. P.; Schultes, C. M.; Morjani, H.; Riou, J.F.; Neidle, S. Biochem. Pharmacol. 2007, 74, 679.

(84) Gu, X.-B.; Nakano, S.; Sugimoto, N. Chem. Commun. (Camb.) 2007, 2750.

(85) Rubis, B.; Holysz, H.; Gladych, M.; Toton, E.; Paszel, A.; Lisiak, N.; Kaczmarek, M.; Hofmann, J.; Rybczynska, M. Mol. Biol. Rep. 2013, 40, 4995.

(86) Del Poeta, G.; Venditti, A.; Del Principe, M. I.; Maurillo, L.; Buccisano, F.; Tamburini, A.; Cox, M. C.; Franchi, A.; Bruno, A.; Mazzone, C.; Panetta, P.; Suppo, G.; Masi, M.; Amadori, S. Blood 2003, 101, 2125.

(87) D’Amours, D.; Sallmann, F. R.; Dixit, V. M.; Poirier, G. G. J. Cell Sci. 2001, 114, 3771.

(88) Maida, Y.; Yasukawa, M.; Okamoto, N.; Ohka, S.; Kinoshita, K.; Totoki, Y.; Ito, T. K.; Minamino, T.; Nakamura, H.; Yamaguchi, S.; Shibata, T.; Masutomi, K. Mol. Cell. Biol. 2014, 34, 1576.

(89) Bodnar, A. G.; Ouellette, M.; Frolkis, M.; Holt, S. E.; Chiu, C.-P.; Morin, G. B.; Harley, C. B.; Shay, J. W.; Lichtsteiner, S.; Wright, W. E. Science 1998, 279, 349.

(90) Vaziri, H.; Benchimol, S. Curr. Biol. 1998, 8, 279. 
(91) Borah, S.; Xi, L.; Zaug, A. J.; Powell, N. M.; Dancik, G. M.; Cohen, S. B.; Costello, J. C.;

Theodorescu, D.; Cech, T. R. Science 2015, 347, 1006.

(92) Dethoff, E. A.; Petzold, K.; Chugh, J.; Casiano-Negroni, A.; Al-Hashimi, H. M. Nature 2012, 491, 724.

(93) Hutton, M.; Lendon, C. L.; Rizzu, P.; Baker, M.; Froelich, S.; Houlden, H.; Pickering-Brown, S.; Chakraverty, S.; Isaacs, A.; Grover, A.; Hackett, J.; Adamson, J.; Lincoln, S.; Dickson, D.; Davies, P.; Petersen, R. C.; Stevens, M.; de Graaff, E.; Wauters, E.; van Baren, J.; Hillebrand, M.; Joosse, M.; Kwon, J. M.; Nowotny, P.; Che, L. K.; Norton, J.; Morris, J. C.; Reed, L. A.; Trojanowski, J.; Basun, H.; Lannfelt, L.; Neystat, M.; Fahn, S.; Dark, F.; Tannenberg, T.; Dodd, P. R.; Hayward, N.; Kwok, J. B.; Schofield, P. R.; Andreadis, A.; Snowden, J.; Craufurd, D.; Neary, D.; Owen, F.; Oostra, B. A.; Hardy, J.; Goate, A.; van Swieten, J.; Mann, D.; Lynch, T.; Heutink, P. Nature 1998, $393,702$.

(94) Varani, L.; Hasegawa, M.; Spillantini, M. G.; Smith, M. J.; Murrell, J. R.; Ghetti, B.; Klug, A.; Goedert, M.; Varani, G. Proc. Natl. Acad. Sci. USA 1999, 96, 8229.

(95) Varani, L.; Spillantini, M. G.; Goedert, M.; Varani, G. Nucleic Acids Res. 2000, 28, 710.

(96) Donahue, C. P.; Muratore, C.; Wu, J. Y.; Kosik, K. S.; Wolfe, M. S. J. Biol. Chem. 2006, 281, 23302.

(97) Zheng, S.; Chen, Y.; Donahue, C. P.; Wolfe, M. S.; Varani, G. Chem. Biol. 2009, 16, 557.

(98) Cohen, F. E.; Kelly, J. W. Nature 2003, 426, 905.

(99) Goedert, M.; Spillantini, M. G.; Crowther, R. A.; Chen, S. G.; Parchi, P.; Tabaton, M.; Lanska, D. J.; Markesbery, W. R.; Wilhelmsen, K. C.; Dickson, D. W.; Petersen, R. B.; Gambetti, P. Nat. Med. 1999, 5, 454 .

(100) Morris, H. R.; Perez-Tur, J.; Janssen, J. C.; Brown, J.; Lees, A. J.; Wood, N. W.; Hardy, J.; Hutton, M.; Rossor, M. N. Ann. Neurol. 1999, 45, 270.

(101) Spillantini, M. G.; Murrell, J. R.; Goedert, M.; Farlow, M. R.; Klug, A.; Ghetti, B. Proc. Natl. Acad. Sci. USA 1998, 95, 7737. 
(102) Shammas, M. A.; Koley, H.; Batchu, R. B.; Bertheau, R. C.; Protopopov, A.; Munshi, N. C.; Goyal, R. K. Mol. Cancer 2005, 4, 24.

(103) Ungvarsky, J.; Plsikova, J.; Janovec, L.; Koval, J.; Mikes, J.; Mikesová, L.; Harvanova, D.; Fedorocko, P.; Kristian, P.; Kasparkova, J.; Brabec, V.; Vojtickova, M.; Sabolova, D.; Stramova, Z.; Rosocha, J.; Imrich, J.; Kozurkova, M. Bioorg. Chem. 2014, 57, 13.

(104) Leonetti, C.; Amodei, S.; D’Angelo, C.; Rizzo, A.; Benassi, B.; Antonelli, A.; Elli, R.; Stevens, M. F.; D’Incalci, M.; Zupi, G.; Biroccio, A. Mol. Pharmacol. 2004, 66, 1138.

(105) Mikami-Terao, Y.; Akiyama, M.; Yuza, Y.; Yanagisawa, T.; Yamada, O.; Yamada, H. Cancer Lett. 2008, 261, 226.

(106) Pennarun, G.; Granotier, C.; Gauthier, L. R.; Gomez, D.; Hoffschir, F.; Mandine, E.; Riou, J.-F.; Mergny, J.-L.; Mailliet, P.; Boussin, F. D. Oncogene 2005, 24, 2917.

(107) Cao, Y.; Li, H.; Deb, S.; Liu, J.-P. Oncogene 2002, 21, 3130. 